\title{
ANCYLIDAE (GASTROPODA, BASOMMATOPHORA) NA AMÉRICA DO SUL: SISTEMÁTICA E DISTRIBUIÇÃO ${ }^{1}$
}

\author{
Rosane Lanzer ${ }^{2}$
}

\begin{abstract}
South American Ancylidae (Gastropoda, Basommatophora): SYSTEMATIC AND DISTRIBUTION. The family Ancylidae is represented in South America by the genera: Gundlachia Pfeiffer, 1849, Ferrissia Walker, 1903, Burnupia Walker, 1912 and Laevapex Walker, 1903. The species are caracterized using the combination of shell features and radula by scanning electron microscope, shell muscle and mantle pigmentation. The conchometry is also presented, but it does not help to species identification. The distribution of G. crequi (Bavay, 1904), G. foncki (Philippi, 1866), G. philippiana (Biese, 1948), G. obliqua (Broderip \& Sowerby, 1832), G. moricandi (Orbigny, 1837), G. concentrica (Orbigny, 1835), G. radiata (Guilding, 1828), G. bakeri Pilsbry, 1913, G. licaga (Marcus \& Marcus, 1962), F. gentilis Lanzer, 1991, B. ingae Lanzer, 1991, L. vazi Santos, 1989 and Laevapex sp. in the Neotropical region is based on the bibliography, examination of the material deposited in scientific institutions and in the author's collection.
\end{abstract}

KEY WORDS. Ancylidae, systematic, distribution, South America

Os Ancylidae são, juntamente com Planorbidae, Lymnaeidae e Physidae, um grupo de distribuição antiga e de origem desconhecida, tendo muitos representantes fósseis desde o Paleoceno da Europa e América do Norte (ZILCH 1959). Na América do Sul, PARodiz (1969) menciona Paleoancylus humboldti (Mayer-Eymar) do Eoceno inferior do Chile.

BOURGUIGNAT (1853) foi o primeiro a colocar a escultura apical como uma peculiaridade do gênero Ancylus Müller, 1774. WALKER (1903, 1912) descreve Ferrissia Walker, 1903 e Burnupia Walker, 1912, distinguindo os gêneros pelo tipo de escultura do ápice. A escultura superficial das conchas tem importância na determinação de espécies (BURCH 1974; HARRISON 1983; LANZER 1989, 1990, 1991). A posição dos músculos adutores da concha foi empregada por BURCH (1962) na classificação genérica de Ancylidae.

Os caracteres da rádula foram utilizados por diferentes autores nas descrições de gêneros e espécies (PILSBRY 1924; WALKER 1924; HUBENDICK 1964; HARRISON 1983; LANZER 1991, 1995).

O estado atual da sistemática de Ancylidae neotropicais é resumido por HUBENDICK (1967) o qual agrupa os 64 nomes existentes em nove form-groups, tendo como base caracteres da concha, pigmentação do manto e a distribuição geográfica. Destes nove grupos, sete são registrados para a América do Sul, todos pertencentes ao gênero Gundlachia Pfeiffer, 1849. O gênero Ferrissia foi referido

1) Parte da tese de doutorado, junto a Universidade do Saarland (Alemanha).

2) Institut für Gewässerökologie und Planung. Keltenweg 39, 66125 Saarbrücken, Alemanha. 
para o continente por PILSBRY (1924) e KLEEREKOPER (1955), sendo nominada somente uma espécie para o sul do Brasil (LANZER 1991). LANZER $(1989,1991)$ registra, pela primeira vez, para a América do Sul o gênero Burnupia até então conhecido somente para África (WALKER 1924; BROWN 1980; VAN DAME 1984). Laevapex Walker, 1903, considerado por BANARESCU (1992) endêmico para América do Norte, é também encontrado na América do Sul, citado primeiramente por SANTOS (1989) para São Paulo.

Neste estudo utiliza-se uma classificação específica, baseada na combinação dos seguintes caracteres: concha e rádula, analisados ao microscópio eletrônico de varredura (MEV), conquiliometria, músculos adutores da concha e padrão de pigmentação do manto. $\mathrm{O}$ trabalho fornece a descrição das espécies, segundo estas características, e sua distribuição geográfica.

\section{MATERIAL E MÉTODOS}

A distribuição das espécies está baseada na literatura, em coletas próprias e no material de coleção das seguintes instituições: The Natural History Museum, Londres, Inglaterra (BMNH); Senckenberg Museum, Frankfurt, Alemanha (SMF); Zoologische Sammlung des Bayerischen Staates, Munique, Alemanha (ZSM); Instituto Miguel Lillo, Tucuman, Argentina (IML); Museo de La Plata, La Plata, Argentina (MLP); Museo Nacional de Historia Natural de Montevideo, Montevideo, Uruguai (MNHM); Museu Nacional do Rio de Janeiro, Rio de Janeiro, Brasil (MNRJ); Museu de Zoologia da Universidade de São Paulo, São Paulo, Brasil (MZUSP); setor de Limnologia do Instituto Ambiental do Paraná (IAP); em Curitiba e Toledo, Paraná, Brasil; Equipe de Equistossomose, Instituto Nacional de Pesquisas da Amazônia (INPA); Manaus, Brasil; Museu de Ciências Naturais da Fundação Zoobotânica do Rio Grande do Sul, Porto Alegre (MCN); Museu de Ciências da Pontifícia Universidade Católica do Rio Grande do Sul, Porto Alegre, Brasil (MCT/PUC-RS).

O método utilizado para preparação de conchas e rádulas para exame ao MEV está descrito em LANZER (1990, 1991, 1995). A descrição da concha e da rádula ao MEV para Gundlachia radiata (Guilding, 1828) e G. obliqua (Broderip \& Sowerby, 1832) baseia-se em HARRISON (1983) e OHL WEILER \& LANZER (1993), respectivamente.

As conchas foram medidas com ocular micrometrada em aumento de seis vezes. Os índices calculados para as medidas das conchas foram: altura pelo comprimento $(\mathrm{A} / \mathrm{C})$ e altura pela largura $(\mathrm{A} / \mathrm{L})$. A conquiliometria fornecida para G. foncki (Philippi, 1866) está baseada em HuBENDICK (1967) e BIESE (1948) e para G. philippiana (Biese, 1948) em BIESE (1948).

As figuras 30 e 31 foram feitas com auxílio do programa de estatística SPSS/PC, utilizando-se o cálculo dos percentis.

$\mathrm{O}$ estudo da concha e rádula ao $\mathrm{MEV}$, a conquiliometria e os músculos adutores estão baseados no seguinte material: G. crequi (Bavay, 1904): Bolívia, Ulla Ulla: Lago Catantira, 87 ex., 16.IV.1983, Schäfer \& Lanzer leg., (3 ex. doados ao SMF); Lago Jankokhala, 4 ex., 18.IV.1983, Lanzer \& Schäfer leg.; Lago Akjata, 
8ex., 20.IV.1983, Lanzer \& Schäfer leg.; Lago não denominado, a 4615m, 7ex., 23.IV.1983, Lanzer \& Schäfer leg. e Laguna Verde, 18 ex., 22.IV.1983, Lanzer \& Schäfer leg. .

Gundlachia obliqua (Broderip \& Sowerby, 1832): MCN 2751, MCN 3019, MCN 32868, MCN 32869, BMNH 185412.4281.

Gundlachia radiata (Guilding, 1828): Brasil, Amazonia: rio Solimões, Ilha da Marchantaria, 29.IX.1987, 24 ex., Lanzer \& Schäfer leg. .

Gundlachia ticaga (Marcus \& Marcus, 1962): MCN 7506; Brasil, Rio Grande do Sul: Cachoeirinha, Rio Gravataí, km 19, 2 ex., 14.I.1982, Pineda leg., (4 ex. doados ao ZSM); Tramandaí, Lagoa Gentil, 3 ex., 27.X.1987, Lanzer leg.; Rio Grande, Lagoa Jacaré, 3 ex., 21.IV.1979, Chomenko leg.; idem, 10 ex., 11.X.1987, Lanzer leg.

Gundlachia bakeri Pilsbry, 1913: Brasil, Amazônia: Igarapé dos Peruanos (Coleção do INPA), Amazônia, 5 ex., 18.VIII.1987, Equipe de Esquistossomose do INPA leg..

Gundlachia moricandi (Orbigny, 1837): Brasil, Rio Grande do Sul: Torres, Lagoa Itapeva, 6 ex., 26.VIII.1980, Lanzer leg.; Osório, Lagoa do Peixoto, 2 ex., 14.X.1984, Lanzer \& Hase leg.; Lagoa Caieras, 32ex., 13.X.1984, Lanzer \& Nunch leg.; Lagoa do Lessa, 18 ex., 13.X.1984, Schäfer \& Hase leg.; Lagoa Caconde, 23 ex., 11.IV.1981, Schäfer leg.; Tramandaí, Lagoa Gentil, 18 ex., 25.III.1984, Chomenko \& Lanzer leg.; Pinhal, Lagoa Cerquinha, 20 ex., 26.III.1984, Lanzer \& Chomenko leg.; idem, 8 ex., 13.III.1981, Schwarzbold \& Oliveira leg.; Palmares do Sul, Lagoa Rincão das Éguas, 35 ex., 21.I.1982, Lanzer \& Chomenko leg.; idem, 9 ex., 12.III.1981, Schäfer leg.; Lagoa Porteira, 30.I.80, Lanzer leg.; idem, 19 ex., 30.XI.1984, Lanzer \& Nunch leg.; Lagoa Capão Alto, 15 ex., 7.III.1981, Schäfer leg.; Lagoa dos Barros, 70 ex., 30.III.1981, Schäfer leg.; São José do Norte, Lagoa Bojuru Velho, 49 ex., 9.II.1984, Atz \& Lanzer leg., (5 ex. doados ao SMF e 7 ex. ao BMNH); Rio Grande, Lagoa Jacaré, 17 ex., 10.I.1981, Schäfer leg.; idem, 34 ex., 12.III.1981, Lanzer \& Schäfer leg.; Lagoa Nicola, 5 ex., 2.XII.1981, Lanzer \& Pineda leg.; idem, 46 ex., 23.IX.1981, Lanzer leg.; idem, 20 ex., 17.XI.1981, Lanzer $\&$ Schäfer leg.;

Gundlachia concentrica (Orbigny, 1835): MCN 5201, MCN 5360, MCN 5617, MCN 5621, MCN 5701, MCN 5800; Brasil, Rio Grande do Sul: Rio Grande, Lagoa Jacaré, 5 ex., 15.VII.1980, Lanzer leg.; idem, 5 ex., 27.X.1980; idem, 10 ex., 16.XI.1980; idem, 8 ex., 10.XII.1980; idem, 37 ex., 12.VIII..1981 (7 ex. doados ao Dr. Hubendick do Museu de História Natural de Göteborg, Suécia); idem, 22 ex., 23.IX.1981; idem, 7 ex., 04.XII.1981.

F. gentilis Lanzer, 1990: MCN 31008 a 31012, MCN 31015 a 31019, SMF 307485 a 307486.

B. ingae Lanzer, 1990: MCN 31014, MCN 31020 a MCN 310334, SMF 301481 a 307484 .

Laevapex sp.: Brasil, Paraná: Itaipú, Rio Ocoí, 7 ex., 27.IX.1988, R.G.N. Loyola leg. .

Além dos lotes doados a museus, o restante do material coletado está depositado na coleção da autora. 


\section{RESULTADOS E DISCUSSÃO}

\section{Gundlachia Pfeiffer, 1849}

Gundlachia é um gênero tipicamente Neotropical. Distribui-se desde o Sul dos Estados Unidos (HUBENDICK 1967) até a Patagonia, tendo seu registro mais austral no Lago Argentino ( $46^{\circ}$ S, HYLTON-SCOTT 1963) e sendo encontrado nos Andes até uma altitude de $4615 \mathrm{~m}$ (LANZER 1990). BRANDT (1974) cita Gundlachia para a Ásia, com uma espécie conhecida para as províncias de Bangkok, Thonburi e Nan, na Tailândia. HUBENDICK (1970) examinou uma amostra recebida do Dr. Brandt e afirma que, sem dúvida, trata-se de uma espécie introduzida da região Neotropical.

O gênero foi caracterizado pela presença de um septo basal. PFEIFFER (1852) amplia sua diagnose, incluindo as formas pós-septadas. Exemplares septados do gênero cosmopolita Ferrissia, o qual também pode desenvolver um septo foram, consequentemente, mencionadas sob o nome de Gundlachia (WALKER 1924; WAUTIER \& ODIEVRE 1961; BURCH 1965).

HUBENDICK (1964) discute a validade e prioridade do gênero Gundlachia em relação aos gêneros Hebetancylus Pilsbry, 1913, Uncancylus Pilsbry, 1913 e Anisancylus Pilsbry, 1924, considerando as diferenças existentes entre os taxa de valor específico. A identidade entre Hebetancylus e Gundlachia já havia sido sugerida por AGUAYo (1946) e HYLTON-SCOTT (1953).

\section{Gundlachia crequi (Bavay, 1904)}

Ancylus crequi Bavay, 1904: 156, fig. 7

Anisancylus lagunarum Haas, 1955: 283, fig. 7

Estudos sobre G. crequi foram efetuados por HAAS (1955), HUBENDICK $(1955,1967)$ e LANZER (1990).

Descrição. A concha de G. crequi é elevada, freqüentemente comprimida lateralmente, com ápice agudo, voltado levemente para a direita e para baixo, sendo que sua projeção, na maioria das vezes, ultrapassa a borda da concha (Fig. 1). Sobre toda a concha há linhas radiais cobertas por pelos do perióstraco que se perdem facilmente no material conservado. O ápice apresenta linhas radiais rudimentares, com pontuações pouco definidas (Fig. 27). O restante da concha, sem o perióstraco, tem linhas radiais leves que cortam as linhas de crescimento irregulares.

O maior exemplar coletado nos andes bolivianos mede $5,2 \mathrm{~mm}$ de comprimento, 2,8mm de largura e 2,8mm de altura.

O manto é, em geral, densamente pigmentado, com coloração que varia do cinza ao preto.

As áreas de inserção muscular anteriores estendem-se transversalmente na região anterior do corpo. A área de inserção muscular posterior esquerda é levemente alongada (Fig. 11).

Os dentes da rádula possuem poucas cúspides, as quais são muito unidas. $\mathrm{O}$ 


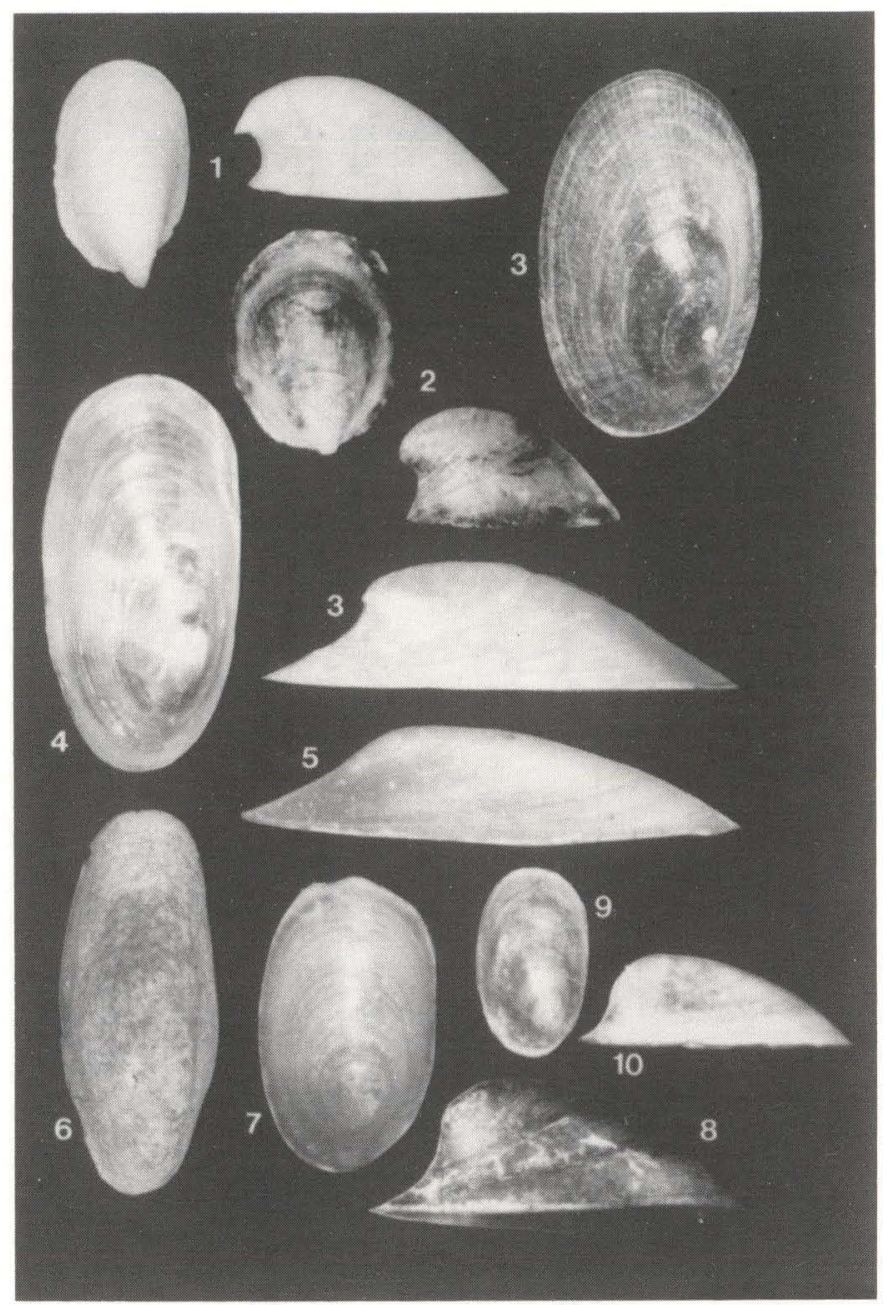

Figs 1-10. Vista dorsal e lateral das conchas de Ancylidae sulamericanos. (1) Gundlachia crequi, Laguna Verde, aumento 8x; (2) G. obliqua, BMNH 185412.4 281, aumento 6,6x (foto de F. Ohlweiler); (3) G. concentrica, Lagoa Jacaré, 12-VIII-1981, aumento $8 x$ (dorsal) e 12x (lateral). (4-6) G. moricandi: (4) Lagoa Rincão das Éguas, aumento 8x; (5) Lagoa dos Barros, aumento $8 x ;(6)$ Lagoa Bojuru Velho, aumento 8x. (7-8) F. gentilis: (7) MCN 31009, parátipo, aumento 12x; (8) MCN 31008, holótipo, aumento 12x. (9-10) B. ingae: (9) MCN 31032, parátipo, aumento $8 x ;(10)$ MCN 31020 , holótipo, aumento 12x.

dente raquidiano tem duas cúspides curtas e os laterais três, separadas somente junto à extremidade (Fig. 27).

Há certa semelhança entre as conchas de $G$. crequi e $G$. concentrica no que se refere, especialmente, às linhas radiais com pelos periostracais e ao ápice agudo. Entretanto, as duas espécies podem ser perfeitamente distinguidas pela microescul- 


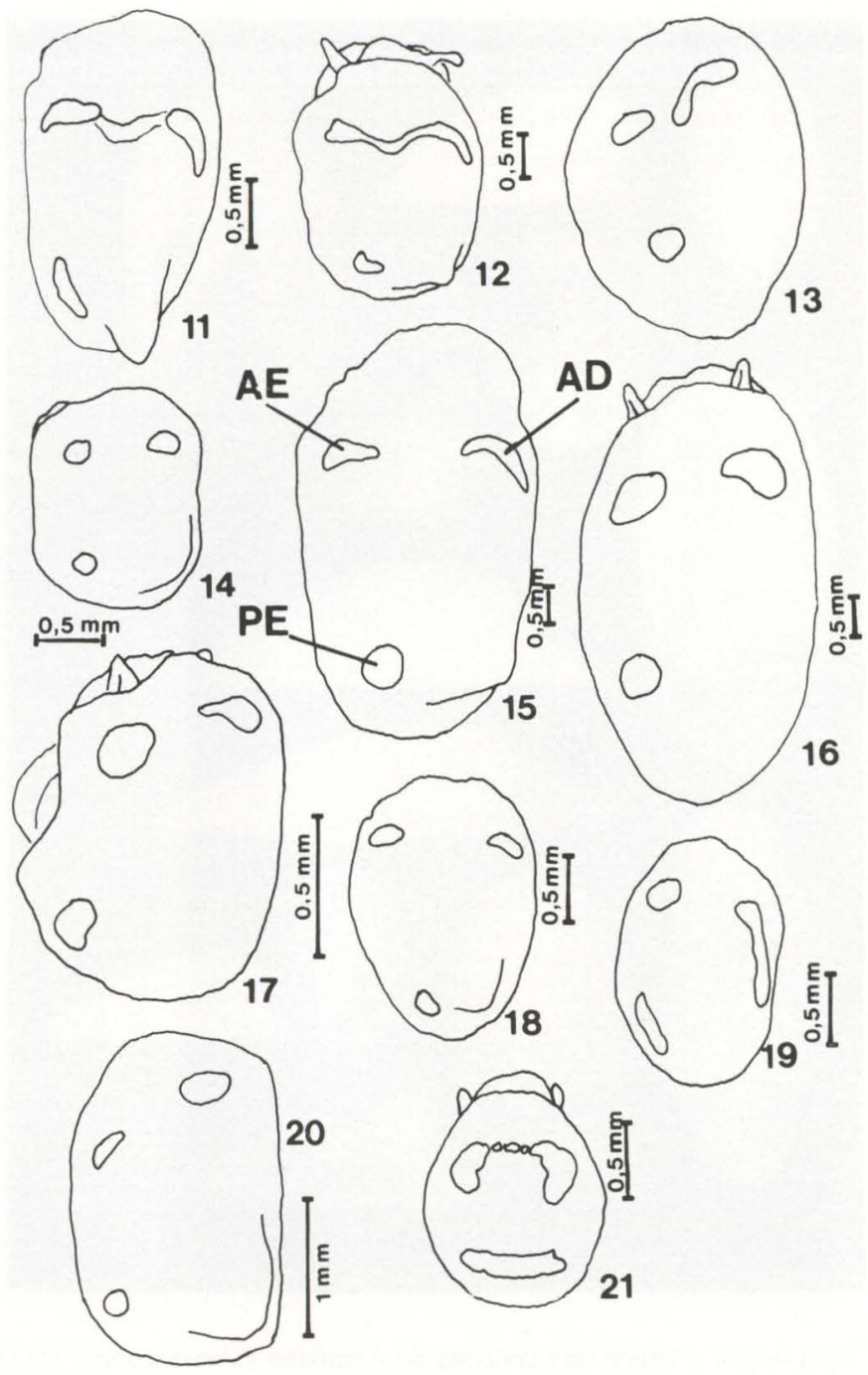

Figs 11-21. Áreas de inserção muscular. (11) Gundlachia crequi, Lago Catantira; (12) G. obliqua (de OHLWEILER \& LANZER 1994); (13) G. radiata (de HARRISON 1983); (14) G. bakeri; (15) G. concentrica, Lagoa Jacaré, 27-X-1980; (16) G. moricandi, Lagoa Bojuru Velho; (17) G. ticaga, Lagoa Gentil; (18) F. gentilis, MCN 31009; (19) B. ingae, SMF 307482; (20) L. vazi (de SANTos 1989); (21) Laevapex sp.. (AE) Anterior esquerdo, (AD) anterior direito, (PE) posterior esquerdo.

tura da região apical e pela relação A/L da concha (Fig. 30-31). A concha de $G$. crequi é mais estreita e elevada. Uma densa pigmentação sobre o manto e áreas de inserção muscular anterior alongadas, unindo-se pelo epitélio adesivo, estão presentes também em G. obliqua. Gundlachia crequi diferencia-se desta pelo ápice, pela 


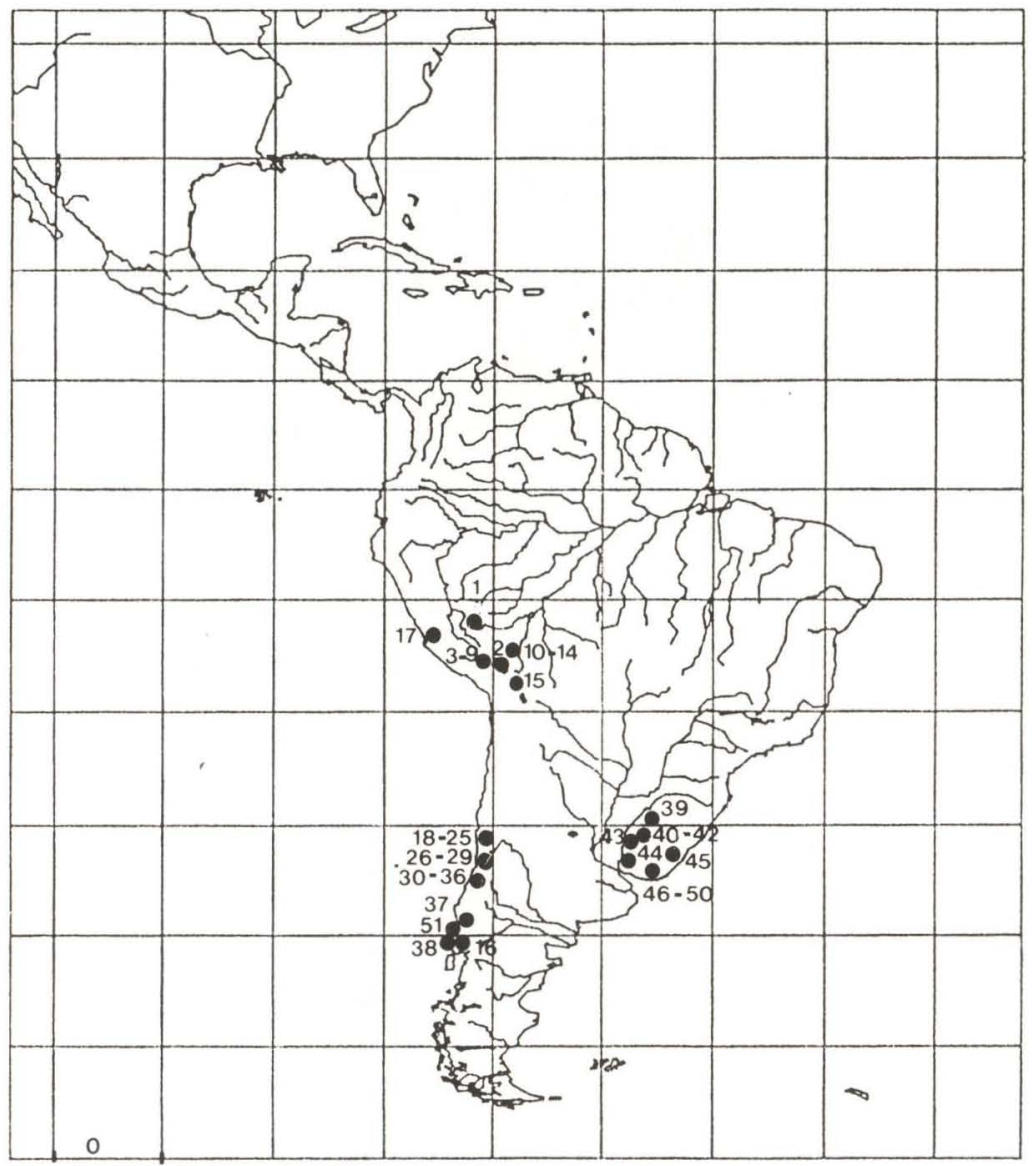

Fig. 22. Ocorrência de Gundlachia crequi (1-15), G. foncki (16), G. obliqua (17-50) e G. philippiana (51) na América do Sul. Peru: (1) Huambualis, Vale de Oropesa; (2) Lago Titicaca; (3) Rio Coata; (4) Laguna Sunuco; (5) Laguna Tejane; (6) Lagunilla Saracocha; (7) Lagunilla Lagunilla; (8) Rio Lagunilla; (9) Rio Saracocha. Bolívia: La Paz (10) Lago Catantira; (11) Lago Jankokhala; (12) Lago Puyo Puyo; (13) Laguna Verde; (14) Lago Akajata; (15) Rio Desaguadero. Chile: LLanquihue - (16) Rio Maullin e Lago Llanquihue. Peru: (17) Callao. Chile: Coquimbo - (18) Ovalle; (19) El Tranque; (20) Illapel; (21) Salamanca; (22) La Brunina; (23) Mina Llamuco; (24) El Gaucho; (25) Zapallar; Valparaíso - (26) Mélon; (27) Quilhota; (28) Valparaíso; Aconcágua - (29) Bella Vista; Santiago - (30) Capilla Caleu; (31) Estero Til-Til; (32) Estero Dehesa; (33) Arrayan, Cajon Del; (34) Barnechea; (35) Penaflor; (36) Santiago; (37) Concepción; (38) Osorno. Brasil: Rio Grande do Sul: (39) Alegrete; (40) Quaraí; (41) Santana do Livramento. Uruguai: (42) Artigas; (43) Salto; (44) Depto de Rio Negro; (45) Depto Treinta y Tres; (46) Colonia; (47) San José; (48) Canelones; (49) Maldonado; (50) Montevideo. Chile: (51) Valdivia, Rio Cruces. 


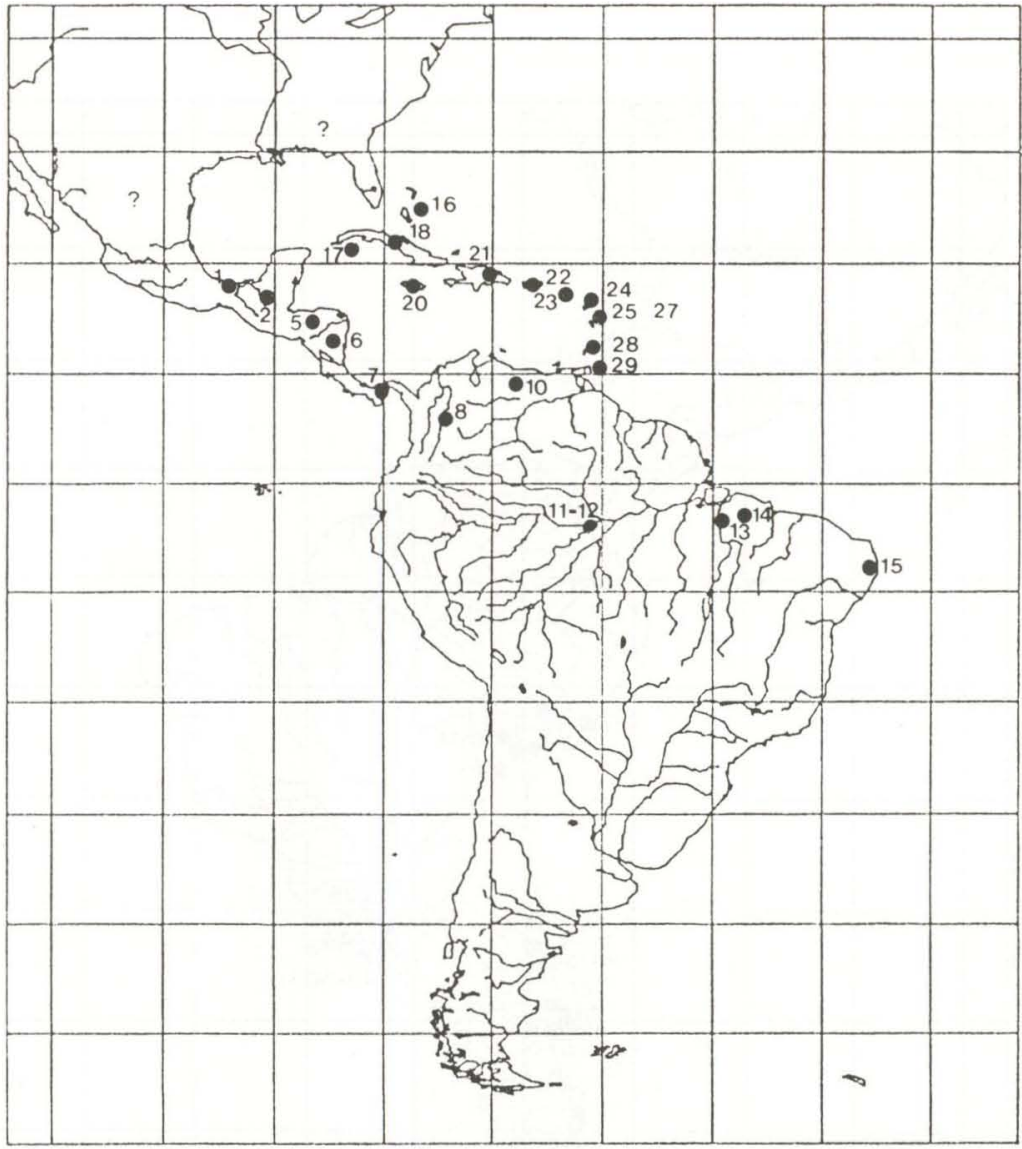

Fig. 23. Ocorrência de Gundlachia radiata na região Neotropical. México: (1) lopolobombeo e Vera Cruz. Guatemala: (2) La Libertad, Péten; (3) Laguna; (4) El Salto. (5) Honduras. (6) Nicarágua. (7) Panamá. (8) Colômbia. Venezuela: (9) Puerto Cabello; (10) Guarico, San Juan de los Morros. Brasil: Amazônia - (11) Rio Solimões, Ilha de Curarí e Lago Januarí; (12) Ilha da Marchantaria; Pará - (13) Tucuruí; (14) Rio Gurupí, Aldeia Coraci; Pernambuco - (15) Salgadinho, próximo a Recife. (16) Bahamas, (17) Ilha dos Pinheiros. (18) Cuba: (19) Gardena. (20) Jamaica. República Dominicana: (21) São Domingo. Porto Rico: (22) Morovis e San German. (23) Antigua. (24) Guadeloupe: Terra Baixa e Terra Grande. (25) Martinica: Fort de France e Rio St. Jacques; (26) St. Lucia: Arroio Chassin; Vale Riche Fond; Rios Canarie, Roseau, Derniere, Castries e Choc; (27) St. Vicente: Mesopotamia, Rio Yambou. (28) Grenada: Rio Chemin. (29) Trinidad. As citações 3, 4, 9 e 19 não foram localizadas.

ausência de estrias radias bem marcadas, sem pelos periostracais, e pela abertura da concha mais oval (Figs 30-31). Os dentes da rádula e a presença de uma única pseudobrânquia são caracteres únicos de G. crequi.

Distribuição (Fig. 22). Gundlachia crequi é conchecida para a Bolívia e Peru, nas localidades: Lago Titicaca, Lago Langui, Lagunilla Lagunilla, Lagunilla Saracocha e outros lagos e pequenos rios na bacia do Lago Titicaca, encontrada em 
profundidade de até $30 \mathrm{~m}$ e a uma altitude de até $4615 \mathrm{~m}$ (HAAS 1955; HUBENDICK 1955, 1967; LANZER 1990; SMF 124891 a SMF 124894, SMF 124924, SMF 147509, SMF 203720, BMNH). A espécie é provavelmente endêmica para esta área. Acredita-se que as figuras 251-253 de HUBENDICK (1967: 42) do vale Oropesa, Huambulis, no Peru, identificadas como G. concentrica, correspondam a G. crequi. Boss (1978) cita-a para a bacia Amazônica, referência certamente obtida de HASS (1955) que menciona o Lago Langui no sistema Amazônico.

\section{Gundlachia foncki (Philippi, 1866)}

Ancylus foncki Philippi, 1866: 38, Biese, 1948: 233, fig. 10

Além da descrição original, não figurada, somente caracteres da concha são encontrados em BIESE (1948) e HUBENDICK (1967).

Descrição. Concha elíptica, larga, com perióstraco de cor castanho claro, com pigmentos escuros, marcada por finas linhas concêntricas de crescimento. O ápice é agudo, levemente à direita da linha mediana, pouco curvado para trás e para baixo, com achatamento dorsal. Sua projeção não ultrapassa a borda da concha (BIESE 1948; HUBENDICK 1967; SMF 151030).

BIESE (1948) encontra na coleção do Museu Nacional de Santiago, Chile, material do Rio Maullín, com etiqueta escrita a mão por Philippi, acreditando ser o lote no qual foi baseada a descrição da espécie. BIESE (1948) não vê, nos 27 exemplares, indícios de estrias radiais as quais, segundo ele, são referidas por PHILIPPI (1866). Na descrição original PHILIPPI (1866: 38) cita “.... striis radiantibus omnino destituta", constatando-se não haver erro.

Os índices calculados a partir das medidas fornecidas por BIESE (1948) e HuBENDICK (1967) para G. foncki são A/C: 0,31-0,38, mediana=0,34 e A/L: $0,52-0,66$, mediana $=0,54(\mathrm{n}=7)$.

BIESE (1948) afirma que as relações entre G. patagonica (Biese, 1948) e $G$. foncki são mais estreitas entre si do que entre G. foncki e G. philippiana (Biese, 1948). As localidades-tipo das duas primeiras espécies situam-se na mesma bacia hidrográfica. Gundlachia patagonica (A/C: 0,34-0,36, mediana 0,35 e A/L: 0,670,74 , mediana 0,72 ) possui conchas mais estreitas que $G$. foncki. Através do exame dos parátipos de G. patagonica (SMF 151031 e BMNH) concorda-se com HUBENDICK (1967) que esta espécie seja uma sinônimo de G. concentrica, embora inexistam estrias radiais e pelos, os quais podem desaparecer no material conservado.

A figura de HuBENDICK (1967: 45, Fig. 258) de G. foncki mostra o ápice voltado para a esquerda. O único exemplar de G. foncki examinado (SMF 151030) tem concha alta, abertura larga, ápice quase mediano e não agudo. Considera-se no presente válida a espécie até que seja feita uma criteriosa revisão.

Distribuição (Fig. 22). Gundlachia foncki não foi registrada fora da sua localidade típica, Rio Maullín e Lago Llanquihue, Província de Llanquihue, no Chile (BIESE 1948; HubENDicK 1967; SMF 151030). 


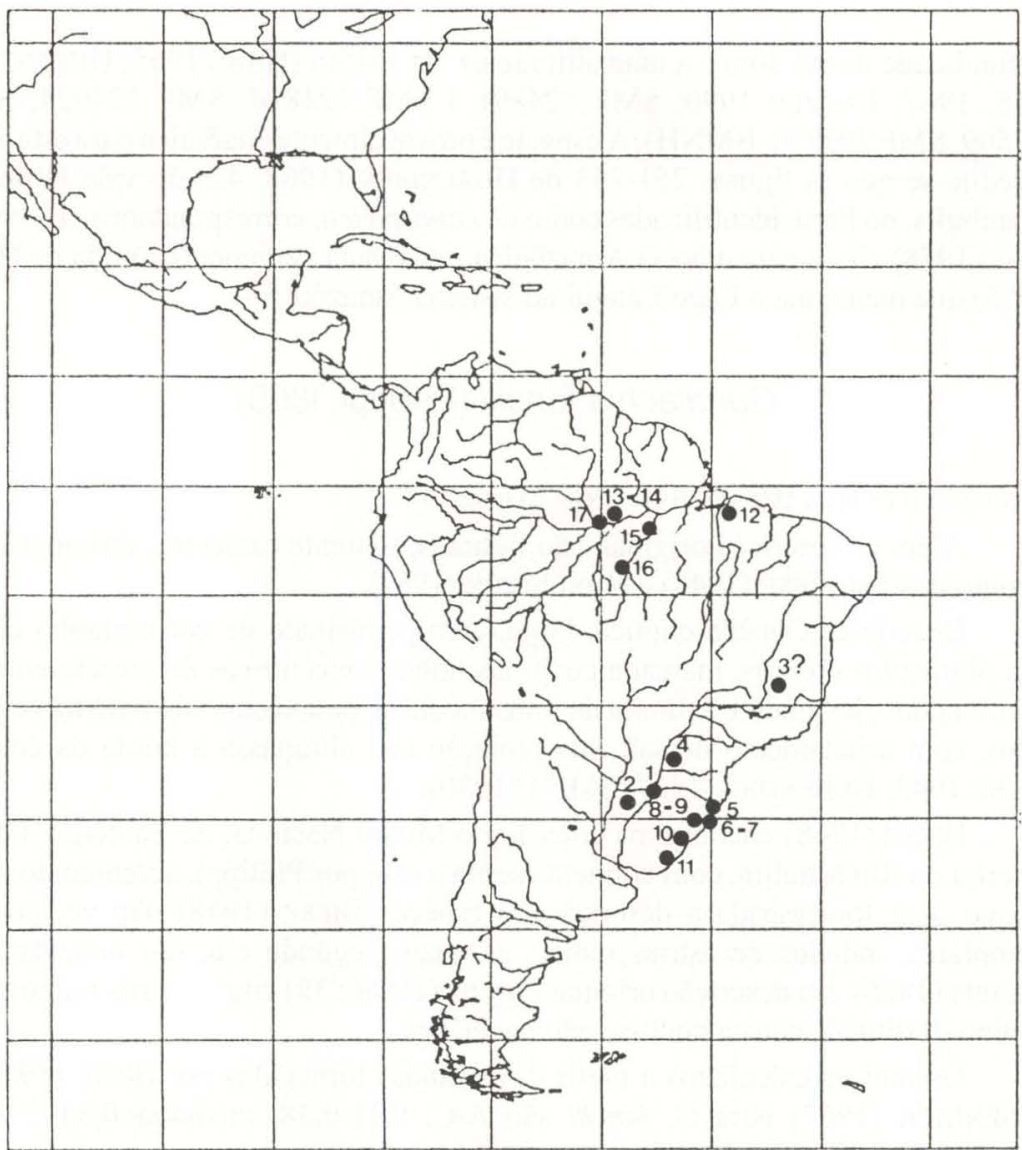

Fig. 24. Ocorrência de Gundlachia ticaga (1-11) e G. bakeri (12-19) na América do Sul. Argentina: (1) Missiones, Arroio Santa Maria; (2) Missiones e Corrientes, Arroio Chimaray. Brasil: Minas Gerais - (3) Lassance (?); Paraná - (4) Toledo, Rio Toldedo; Rio Grande do Sul - (5) Torres, Rio do Forno; (6) Tramandaí, Lagoa Gentil; (7) Santo Antonio da Patrulha, Rio Gravataí e Arroio Chico Lomã; (8) Gravataí; (9) Viamão; (10) Rio Grande, Estação Ecológica do Taim, Lagoa Jacaré e Canal da Sarita; (11) Santa Vitória do Palmar, Banhado do Albardão. Pará - (12) Belém, Thomé-assú, Rio Acará-Pequeno; (13) entre Alenque e Obidos, Lago Tostão; (14) Obidos, Rio Cupari; (15) Fordlândia, Rio Tapajoz; Amazônia - (16) Rio Paracuní, (17) Rio Tarumã Mirím; (18) Igarapé dos Peruanos. A citação 18 não foi localizada.

\section{Gundlachia philippiana (Biese, 1948)}

Ancylus philippianus Biese, 1948: 234, fig. 11

Ancylus valdivianus Philippi nom. nud.

Desta espécie só se conhece a descrição original de BIESE (1948), baseada unicamente em caracteres da concha.

Descrição. Concha delgada, lisa, sem escultura. Ápice no meio do compri- 
mento da concha, muito curto e estreito, pontiagudo, pouco curvado para trás e para baixo. A abertura é elíptica e as extremidades são elevadas (BIESE 1948).

Os índices calculados a partir das medidas de BIESE (1948) são A/C: $0,29-0,33$, mediana $=0,31$ e A/L: 0,41-0,62, mediana $=0,46(n=4)$, demonstrando ser a concha moderadamente alta e larga.

O parátipo examinado (BMNH) combina com a descrição de BIESE (1948), exceto pelo ápice que não é pontiagudo, mas, ao contrário, semelhante ao de $G$. moricandi, só que localizado quase no meio da concha. HUBENDICK (1967) comenta ser esta espécie muito duvidosa e a coloca, com uma interrogação, na lista de sinônimos de G. moricandi. Como G. foncki, deverá ser revisada, permanecendo no presente como espécie válida.

Distribuição (Fig. 22). Rio Cruces, Valdívia, Chile (BIESE 1948).

\section{Gundlachia obliqua (Broderip \& Sowerby, 1832)}

Ancylus obliquus Broderip \& Sowerby, 1832: 202

Ancylus radiatus Orbigny, 1835: 24

Ancylus gayanus Orbigny, 1837: 356, pl. XLII, figs 13-17

Ancylus gayanus var. obliquus Biese, 1948: 229, fig. 7

Ancylus gayanus var. rudolfi Biese, 1948: 232, fig. 9

Ancylus gayanus var. maximus Biese, 1948: 231, fig. 8

Anisancylus obliquus gayanus; Wurtz, 1951

Anisancylus obliquus maximus; Wurtz, 1951

Anisancylus obliquus rudolfi; Wurtz, 1951

Gundlachia obliqua; Hubendick, 1967: 36, figs 191-192

Gundlachia gayana; Hubendick, 1967: 38, figs 195-217

Características conquiliológicas e da morfologia externa são dadas por BIESE (1948) e HUBENDICK (1967). Um estudo amplo da espécie, incluindo sua distribuição, é fornecido por OHLWEILER \& LANZER $(1993,1994)$.

Descrição. A concha é elevada, com ápice conspícuo e obtuso, com achatamento dorsal, levemente voltado para direita e para trás e apresentando pontuações pequenas e arredondadas, dispostas de forma desordenada (Fig. 2, 27). Toda a concha está ornamentada por estrias radiais proeminentes que iniciam no centro do achatamento apical, sendo mais salientes na região ântero-mediana da concha e mais finas e tênues na região apical (OHLWEILER \& LANZER 1993).

O maior exemplar estudado por OHLWEILER \& LANZER (1993) mede $6,5 \mathrm{~mm}$ de comprimento, $4,8 \mathrm{~mm}$ de largura e $2,9 \mathrm{~mm}$ de altura (MCN 32869). A conquiliometria é mostrada nas figuras 30 e 31 .

O manto possui uma pigmentação homogênea que varia do marron ao preto.

A área de inserção do músculo anterior esquerdo estende-se transversalmente na região anterior do corpo, enquanto a esquerda alonga-se, normalmente, até a região látero-mediana do corpo. As áreas de inserção muscular podem unir-se através do epitélio adesivo. O músculo posterior esquerdo tem área de inserção arredondada ou alongada (Fig. 12).

A rádula tem dente raquidiano com duas cúspides principais longas, podendo 


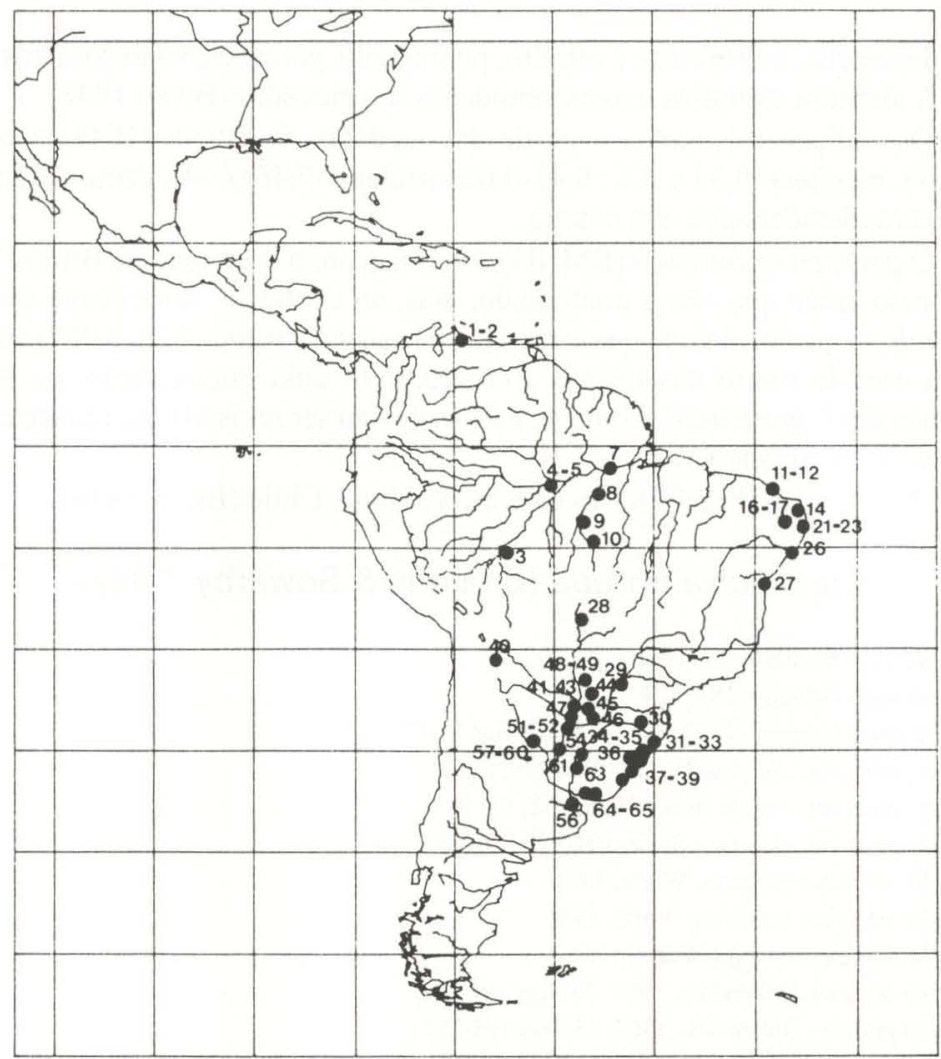

Fig. 25. Ocorrência de Gundlachia moricandi na América do Sul. Venezuela: (1) Lago Valência; (2) Barquisimeto. Brasil: Amazônia - (3) Rio Madeira; (4) Ilha Curari; (5) Rio Amazonas; (6) Rio Candeias; Pará - (7) Rio Amazonas; (8) Rio Cupari; (9) Missão São Francisco de Cururú, Rio Tapajóz; (10) Rio Manoel; Ceará - (11) Fortaleza, Lagoa de Mecejana; (12) Açude Botija; (13) Lima Campos; Rio Grande do Norte -(14) Ceará Mirim; (15) açude Carnuba e Casumba; Paraíba -(16) entre Pombal e Patos; (17) Açude Graritas; (18) Boa Vista; (19) Macaco e Puxinãnã; Pernambuco - (20) Pão d'Alho; (21) Recife; (22) Olinda, Fragoso; (23) Paulista; (24) São Bento, Rio Itapacura; (25) açude Broca; Alagoas: (26) Penedo, Rio Tupurungá; Bahia - (27) Uruçuca (MZUSP); (28) Mato Grosso; Paraná - (29) Itaipu, Rio Ocoi; Santa Catarina - (30) Campos Novos, Rio Canoas; Rio Grande do Sul - (31) Torres: Rio Mampituba; (32) Maquiné, Rio Maquiné; (33) Cambará do Sul, Rio Camisas; (34) Gravataí e Cachoeirinha, Rio Gravataí; (35) Tapes, Laguna dos Patos; (36) Rio Camaquã; (37) Viamão, Lagoa do Casamento; (38) lagoas costeiras de Torres a Santa Vitória do Palmar; (39) Rio Grande, Lagoa Mirim. Bolivia: (40) Caiza e Creveaux. Paraguai: (41) Assunção; (42) Laguna de Assunção; (43) Central, Arroio Ytaí e Abay; (44) Caaguazú, San José de los Arroyos; (45) Villarica, Arroio D. Juana; (46) Itapúa, Rio Aguapey; (47) Neembucú, Rio Negro; (48) San Pedra: Porrotos; (49) Concepción, San Lázaro. Argentina: (50) Ibicuycito; (51) Corrientes; (52) Rio Paraná; (53) Paso Cerrito, Rio Batel; (54) Paso de los Libres, Rio Uruguai; (55) Santo Thomé; (56) La Plata, Rio Santiago; (57) Entre Rios; (58) Santiago del Estero, Chaco; (59) Salta; (60) Formosa; (61) Santa Fé; (62) Rio Uruguai, entre Concórdia e Punta Gorda. Uruguai: (63) Salto, Artigas, Salto Grande; (64) Canelones; (65) Montevideo. 


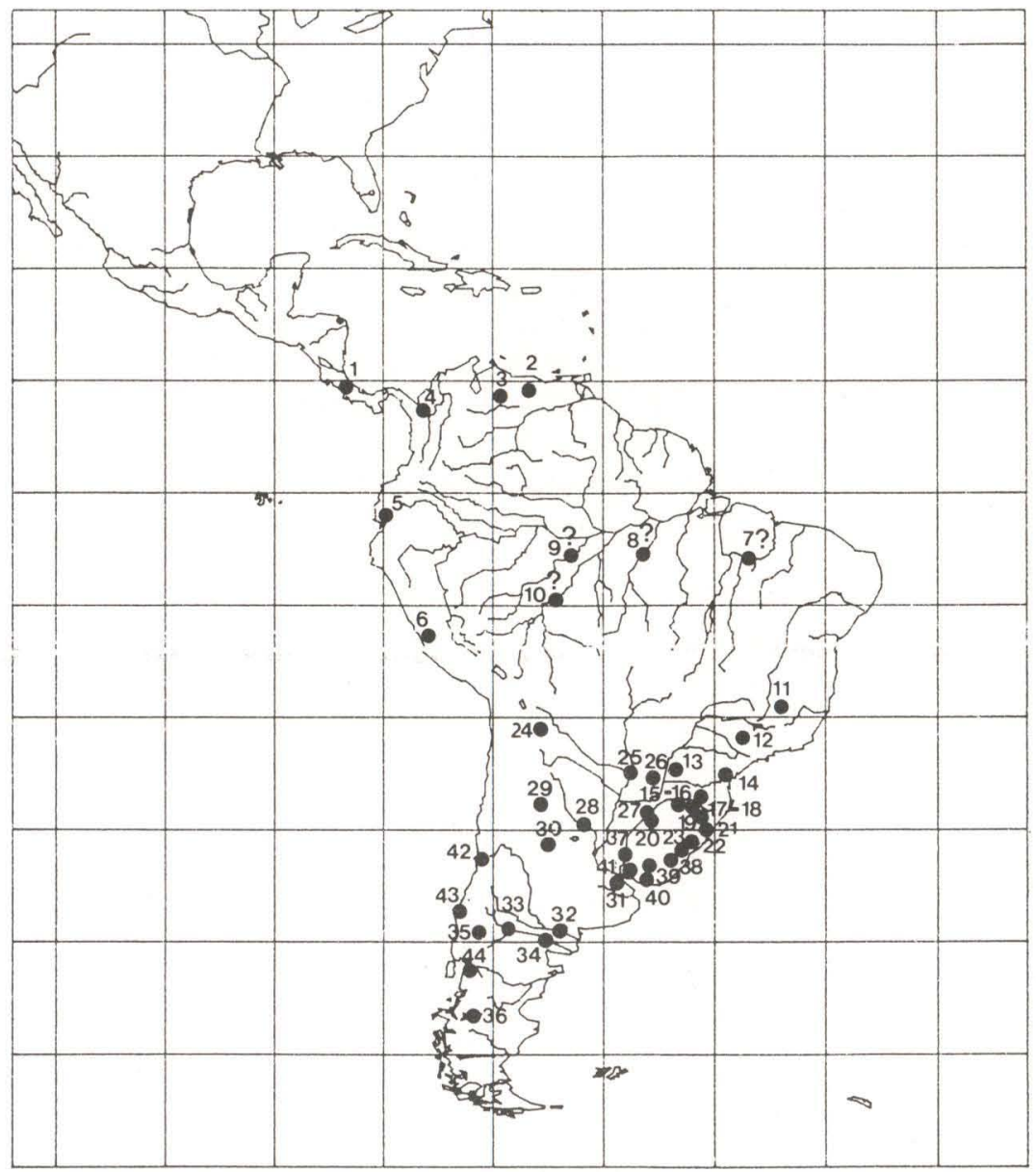

Fig. 26. Ocorrência de Gundlachia concentrica na região Neotropical. Costa Rica: (1) Cartago. Venezuela: (2) Los Teques, Miranda; (3) Guanare, Portuguesa. Colombia: (4) Guaca, Antioquiá (1600m). Equador: (5) Rios de Guayaquil. Peru: (6) Lima, Rio Limac. Brasil: (7-10) Amazônia; (11) Minas Gerais, Pedro Leopoldo; (12) São Paulo, Jaboticabal; Paraná - (13) Toledo, Rio Toledo; (14) Curitiba; Santa Catarina - (15) Campos Novos, Rio Ibicui; (16) Rio Canoa; Rio Grande do Sul - (17) Itá, Rio Uruguai; (18) Espigão Alto, Arroio Marmeleiro; (19) Vacaria, Rio Socorro; (20) Pirapó e Rincão Vermelho, Rio ljuí; (21) Porto Alegre; (22) Rio Camaquan /sic/; (23) Pelotas. Bolívia: (24) Caiza. Paraguai: (25) Assunção; (26) Caaguazu Central. Argentina: (27) San Javier, Arroio Guerrero; (28) Santa Fé, Rio Salado; (29) Tucuman; (30) Córdoba; (31) Buenos Aires; (32) Rio Colorado; (33) Rio Neuquen; (34) Rio Negro; (35) Nahuel Huapi, Lago Gutierrez; (36) Lago Buenos Aires. Uruguai: (37) Rio Uruguai; (38) Cerro Largo; (39) Depto Florida; (40) Depto Canelones e Montevideo, Arroio Pantanoso; (41) Depto Colonia. Chile: (42) El Tranque, Rio Aconcágua; (43) Concepcion; (44) Rio Puelo, Lago Blanco. 
haver uma pequena entre elas. Ao lado da cúspide principal esquerda há uma ou duas cúspides pequenas e ao lado da direita somente uma. Os dentes laterais são tricúspides, com a mediana maior e duas a cinco cúspides menores ao lado das outras duas; uma cúspide pequena pode existir entre essas e a mediana. Os dentes marginais têm até dez cúspides (Fig. 27).

Como já mencionado, G. obliqua apresenta caracteres semelhantes a $G$. crequi e também a $G$. concentrica. As três espécies possuem linhas radiais sobre a concha, sendo que em $G$. obliqua estas linhas são muito mais proeminentes, parecendo costelas e cobrem toda a concha. Nas duas outras espécies, as linhas radiais são tênues e muitas vezes aparecem cobertas por pelos periostracais, além de possuírem ápice agudo. O índice $\mathrm{A} / \mathrm{C}$ mostra que a concha de G. obliqua é mais alta que das outras espécies (Fig. 30). A pigmentação do manto, como referido anteriormente, é muito semelhante àquela encontrada em G. crequi. Os músculos anteriores assemelham-se aos de $G$. concentrica e G. crequi (Figs 11, 12, 15). O dente raquidiano lembra muito o de $G$. concentrica, entretanto, neste último, o número de cúspides ao lado das principais varia de duas a três (Fig. 27).

Distribuição (Fig. 22). Gundlachia obliqua é o Ancylidae mais comum no Chile, vivendo em altitudes de até 1900m (BIESE 1948). Sua área de distribuição inclue ainda Peru, Uruguai e sul do Brasil (BoURGUIGNAT 1853, 1862; HUBENDICK 1967; OLAZARRI 1983; OHLWEILER \& LANZER 1993). BIESE (1948) menciona sua ocorrência desde o Sul da Província de Coquimbo até Santiago, Chile. OHL WEILER \& LANZER (1993) ampliam essa distribuição até Concepción e no presente estudo até Osorno (SMF 106705). No Brasil é conhecida somente no Rio Grande do Sul, para os Municípios de Quaraí, Santana do Livramento e Alegrete e no Uruguai para os Departamentos de Artigas, Salto, Treinta y Tres (OHLwEILER \& LANZER 1993) e Rio Negro, a poucos quilometros de Salto Grande (OlAZARRI 1983).

\section{Gundlachia radiata (Guilding, 1828)}

Ancylus radiatus Guilding, 1828: 536, pl. 26, fig. 7-9

Ancylus havanensis Pfeiffer, 1839: 350

Gundlachia ancyliformis Pfeiffer, 1849: 98

Ancylus chittyi Adams, 1851: 204

?Ancylus excentricus Morelet, 1851: 17

Ancylus radiatilis Morelet, 1851: 17

Ancylus obliquus; Adams, 1852: 48

Ancylus saulcyanus Bourguignat, 1853: 92, pl. XXV, figs 26-33

Ancylus petitianus Bourguignat, 1853: 172, pl. VI, fig. 10

Ancylus pallidus Poey, 1856: 10, 32, pl. 2, fig. 13

Ancylus sallei Bourguignat, 1857: 32

Gundlachia hjalmarssoni Pfeiffer, 1858: 197

Ancylus parasitans Drouët, 1859: 387, pl. 3, figs 39-41

Gundlachia poeyi Bourguignat, 1862: 82, pl. 3, figs 1-4

Gundlachia adelosia Bourguignat, 1862: 83, pl. 3, figs 5-8

Poeyia gundlachioides Bourguignat, 1862: 87, pl.3, figs 15-20

Ancylus adelinus Bourguignat, 1862: 227

Revta bras. Zool. 13 (1): 175 - 210, 1996 
Ancylus pffeiferi Bourguignat, 1862: 229

Ancylus textilis Guppy, 1870: 311. pl. 17, figs 9-11

Ancylus peninsulae Pilsbry \& Jonson, 1896: 138

Ancylus papilaris Martens, 1899: 402

Gundlachia hinkleyi Walker, 1917: 139

?Ferrissia jamaicensis Walker, 1921: 73

Hebetancylus cubensis Pislbry \& Aguayo, 1933: 116

Ferrissia (Laevapex) aquadae Goodrich \& van der Schlalie, 1937: 34, pl. I, figs 7-7a

Ferrissia (Laevapex) haitiana Clench \& Aguayo, 1937: 70

Ferrissia (Laevapex) bahamensis Clench \& van der Schalie, 1938: 318

Hebetancylus providentialis Wurtz, 1951: 127, pl.'4, figs 8, 8a.

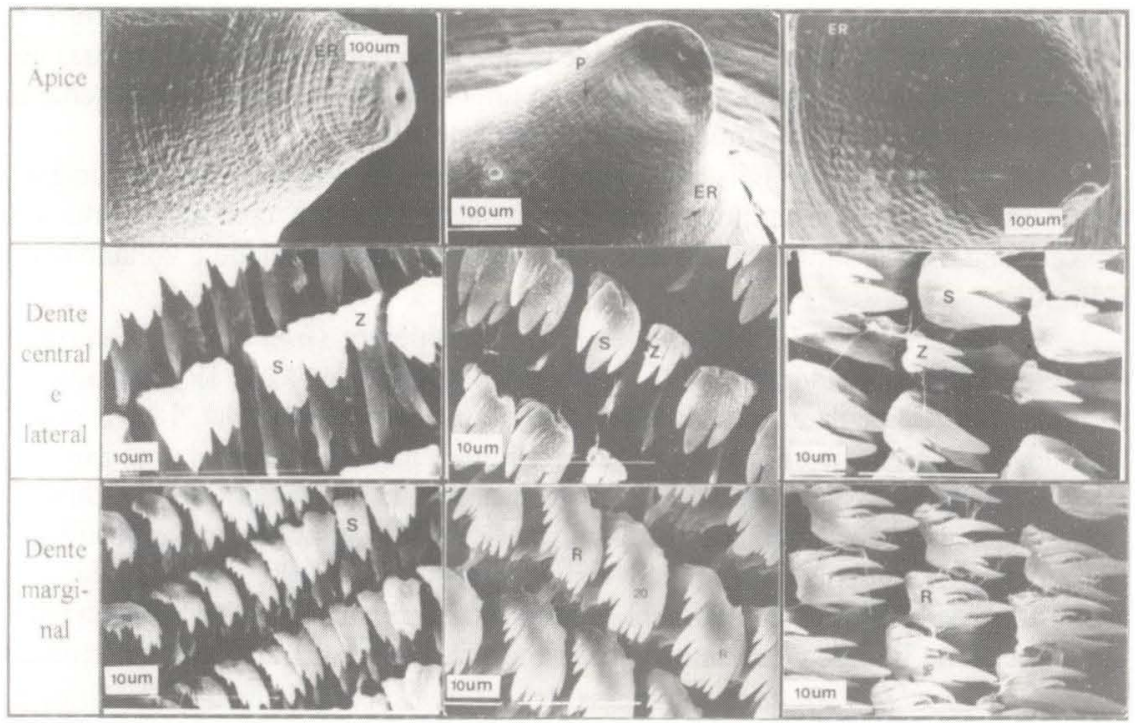

Fig. 27. Aspecto do ápice e da rádula ao microscópio eletrônico de varredura. Gundlachia crequi (esquerda), Lago Catantira, ápice visto de lado; dente raquidiano e laterais; dentes marginais; G. concentrica (meio), Lagoa Jacaré, 12-VIII-1981, ápice visto de lado; dente raquidiano e laterais; dentes marginais; G. obliqua (direita), MCN 32868, ápice visto de cima; dente raquidiano e laterais, MCN 3019; dentes marginais. (ER) Estrias radiais; (P) pontuações; (Z) dente raquidiano; (S) dente lateral; $(\mathbf{R})$ dente marginal; os números indicam a posição do dente na fileira.

Gundlachia radiata está amplamente distribuída pela América Central. HARRISON (1983) revisa a espécie, ampliando sua diagnose com caracteres da concha e rádula, analisados ao MEV.

Descrição. A concha tem forma bastante variada, podendo ser mais ou menos elevada. O ápice é obtuso, achatado, localizado à direita da linha mediana, com projeção nunca ultrapassando a borda da concha. A concha embrionária apresenta 
pontuações desordenadas, enquanto o restante da concha tem, além das linhas de crescimento, linhas radiais que iniciam além dos limites da concha embrionária. Estas linhas são espaçadas e salientes, cobrindo toda a concha ou restritas à região anterior (HARRY \& HUBENDICK 1964; HUBENDICK 1967; HARRISON 1983).

O manto tem pigmentação rica e irregular (HARRY \& HUBENDICK 1964; HUBENDICK 1967; HARRISON 1983).

As áreas de inserção dos músculos anterior e posterior esquerdo (Fig. 13) são quase do mesmo tamanho, sendo a posterior arredondada e a anterior amendoada (HARRISON 1983). A área de inserção anterior direita é maior e tem forma de um V, aberto e invertido (Fig. 13) (HUBENDICK 1964, 1967; HARRISON 1983).

De acordo com a descrição e a figura de HARRISON (1983), no dente raquidiano há uma cúspide menor, muito raramente duas, a cada lado das duas principais, sem uma cúspide pequena entre elas. Os dentes laterais têm, entre a cúspide mediana e a externa, uma cúspide pequena no dente da esquerda e duas no da direita e, entre a mediana e a interna, há uma cúspide pequena; lateralmente à cúspide externa observa-se uma ou duas cúspides pequenas.

HUBENDICK (1967) discute a presença de duas formas distintas de conchas em $G$. radiata: uma forma típica, com concha baixa, achatada, com ápice obtuso e uma concha mais assimétrica, elevada, com ápice mais pronunciado e voltado para a direita.

WURTZ (1951) e HUBENDICK (1967) consideram Gundlachia excentrica (Morelet, 1851) um sinônimo de G. radiata. BURCH \& LOVERDE (1974) analisam a escultura do ápice da concha de Hebetancylus excentricus Morelet, 1851, observada ao MEV, e verificam que a 0,1-0,2mm do ápice partem ranhuras radiais, muito rasas e curvadas. Estas observações são contrárias ao constatado por HARRISON (1983) que descreve a concha embrionária de G. radiata, procedente da localidade tipo, com orifícios pequenos e numerosos. HUBENDICK (1967) menciona, ainda, que a escultura radial pode estar totalmente ausente no excentrica type. Até que seja feita uma revisão do tipo de $G$. excentrica permanecerá dúvida quanto a esta sinonimia.

Gundlachia radiata distingue-se de outras espécies pelo tipo de ápice e estrias radiais espaçadas, além da forma característica de sua área de inserção muscular direita. Embora em G. ticaga e G. bakeri o ápice também seja arredondado e pontuado, na primeira há somente linhas de crescimento e na segunda as linhas radiais estão dispostas em uma leve espiral e o manto tem pigmentação fraca. Quanto a sua conquiliometria, a amostra medida de $G$. radiata assemelha-se a de $G$. moricandi, por apresentar concha mais baixa e mais larga (Figs 30-31). Entretanto, nesta última o ápice é sempre liso.

Distribuição (Fig. 23). Se G. excentrica for um sinônimo de G. radiata, a área de distribuição desta espécie estende-se do sul dos Estados Unidos (Texas, Georgia, Flórida) ao norte da América do Sul (BASCH 1963; HuBENDICK 1967), caso contrário o limite norte de ocorrência será o México. Gundlachia radiata é registrada para o México, Guatemala, Honduras, Nicarágua, Panamá, Bahamas, Ilha dos Pinheiros, Cuba, Jamaica, República Dominicana, Porto Rico, Antigua, Guadeloupe, Martinica, St. Lucia, St. Vicent, Grenada, Trinidad, Colômbia, Venezuela e Brasil (Crosse 1891; SMith 1895; GoOdrich \& VAN DER SCHAlie 1937; 


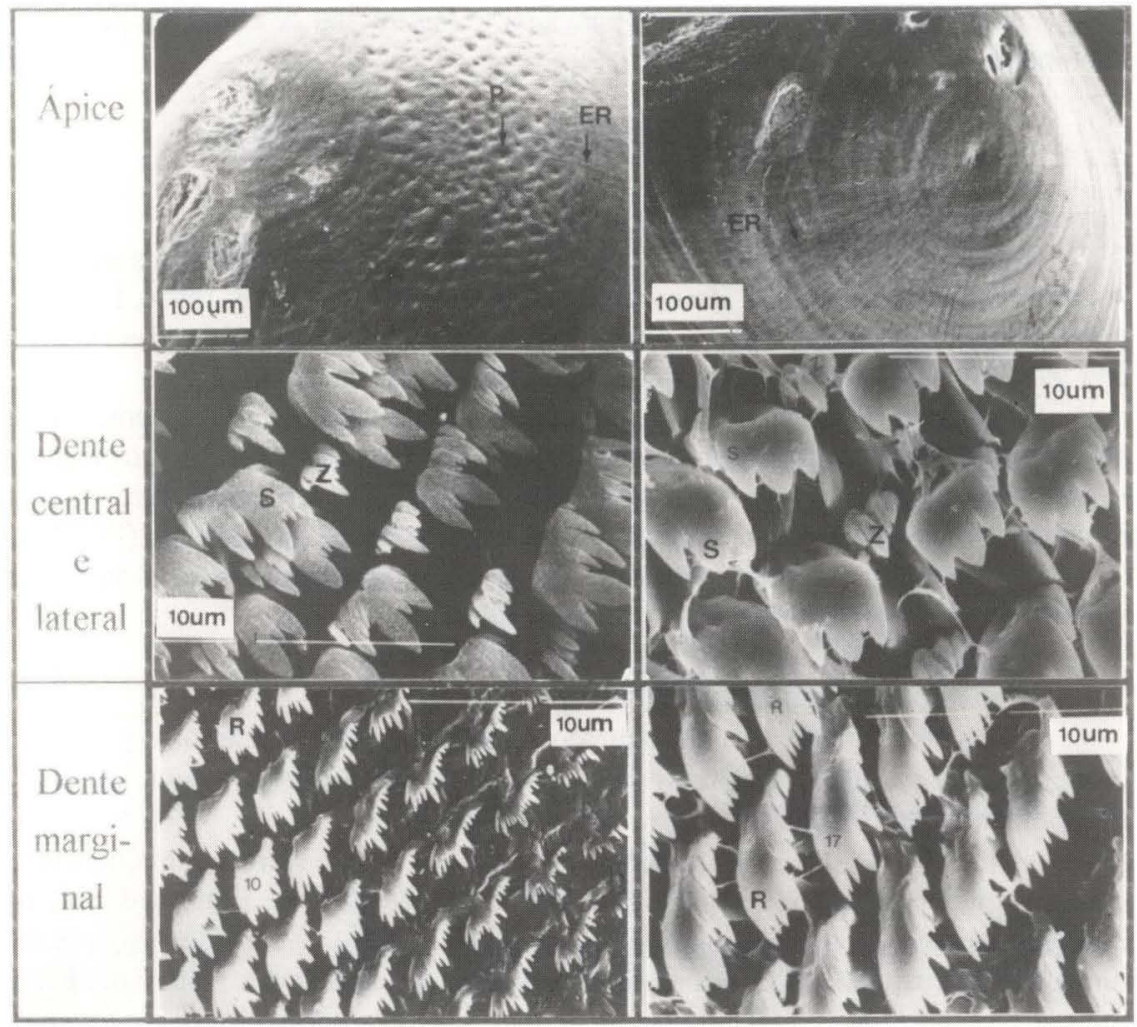

Fig. 28. Aspecto do ápice e da rádula ao microscópio eletrônico de varredura. Gundlachia ticaga (esquerda), Rio Gravatai, ápice visto de lado; dente raquidiano e laterais, MCN 7506; dentes marginais; G. moricandi, Laguna dos Patos, Tapes, ápice visto de cima; dente raquidiano e laterais, Lagoa do Peixoto; dentes marginais. (P) Pontuações; $(Z)$ dente raquidiano; (S) dente lateral; (R) dente marginal; os números indicam a posição do dente na fileira.

Aguayo 1938, 1966; HARRY \& HUBENDICK 1964; HuBENDICK 1964, 1967; IRMLER 1975; POINTIER 1976; GUYARD \& POINTIER 1979; HARRISON 1983; MALEK 1986; SMF 149949, SMF 177877, SMF 203715). IRMLER (1975) cita para o Rio Solimões Laevapex aguadae/sic/ Goodrich \& van der Schalie, 1937 que é um sinônimo de G. radiata, segundo HUBENDICK (1967). Esta ocorrência pôde ser confirmada por coleta própria efetuada próximo à Ilha da Marchantaria (setembro de 1987). SANTOS (com. pes. 1987) encontrou a espécie em Tucuruí, no Pará. Identificou-se como G. radiata o lote MZUSP do Rio Gurupí, Aldeia Coraci, no Pará. O lote SMF 44352 referido por HAAS (1939) como Burnupia (Uncancylus) barilensis (Moricandi, 1845) para Pernambuco é G. radiata. 
A espécie parece restrita a região tropical do continente sulamericano, não sendo conhecida para os Andes nem para a parte meridional de clima temperado e subtopical.

\section{Gundlachia ticaga (Marcus \& Marcus, 1962)}

Uncancylus ticagus Marcus \& Marcus, 1962: 217, pl. 1-4, figs 1-19

MARCUS \& MARCUS (1962) fornecem uma descrição detalhada da espécie. A rádula e a concha ao MEV são caracterizadas por LANZER $(1989,1995)$. LANZER (1989) estuda a concha e rádula, apresentando aspectos do habitat de uma espécie de Gundlachia não denominada a qual identifica-se com G. ticaga.

Descrição. A concha é alta, com ápice arredondado e proeminente, com achatamento dorsal e apresentando uma banda de orifícios dispostos irregularmente. O ápice é bastante recurvado, com projeção ultrapassando, frequentemente, a borda da concha. Na teleoconcha há somente linhas concentricas de crescimento (Fig. 28).

O tamanho máximo constatado na amostra estudada foi de $4,5 \mathrm{~mm}$ de comprimento, $2,9 \mathrm{~mm}$ de largura e $1,3 \mathrm{~mm}$ de altura.

Os índices são mostrados nas figuras 30 e 31 .

O manto tem pigmentação esparsa.

As áreas de inserção muscular são pequenas, sendo a anterior e posterior esquerda arredondadas e a anterior direita em forma de uma gota d'água, disposta transversalmente. (Fig. 17).

A rádula de G. ticaga tem o dente raquidiano acentuadamente assimétrico, com a cúspide principal esquerda muito mais longa que a direita. Entre elas há uma cúspide pequena, fina e tão longa quanto a direita. Ao lado da cúspide esquerda há uma ou duas cúspides pequenas. Os dentes laterais são tricúspides, com a mediana mais larga e mais longa que outras duas, as quais têm uma a duas cúspides pequenas lateralmente. Entre elas e a mediana há uma cúspide pequena muitas vezes subdividida. Os dentes marginais possuem até 13 cúspides, finas e alongadas, reduzindo drasticamente seu tamanho junto à extremidade (Fig. 28).

Gundlachia ticaga assemelha-se a G. radiata, G. concentrica, G. obliqua e G. bakeri pela presença comum de pontuações no ápice. Entretanto, essas quatro espécies são perfeitamente diferenciadas pela forma de seu ápice e estrutura da teleoconcha, onde, exceto em G. bakeri, há estrias radiais. De acordo com MARCUS \& MARCUS (1962), em somente algumas das 50 conchas examinadas foram observadas linhas radiais produzidas por leves costelas sobre a superfície interna da concha o que se confirma no material examinado. WALKER (1925) descreve um Ancylidae o qual não denominou e que foi coletado em Lassance, norte de Minas Gerais, junto com Gundlachia lutzi Walker, 1925 a qual foi descrita com base em um único espécimen septado. O Ancylidae não denominado pode, segundo WALKER (1925: 6, figs 10-11), corresponder a forma não septada de G. lutzi. MARCUS \& MARCUS (1962) afirmam que este Ancylidae referido por WALKER (1925) assemelha-se a Uncancylus ticagus. A descrição de WALKER (1925) menciona um ápice obtuso, pontuado, ausência de estrias radiais na superfície da concha e a presença de linhas de crescimento finas e regulares. 


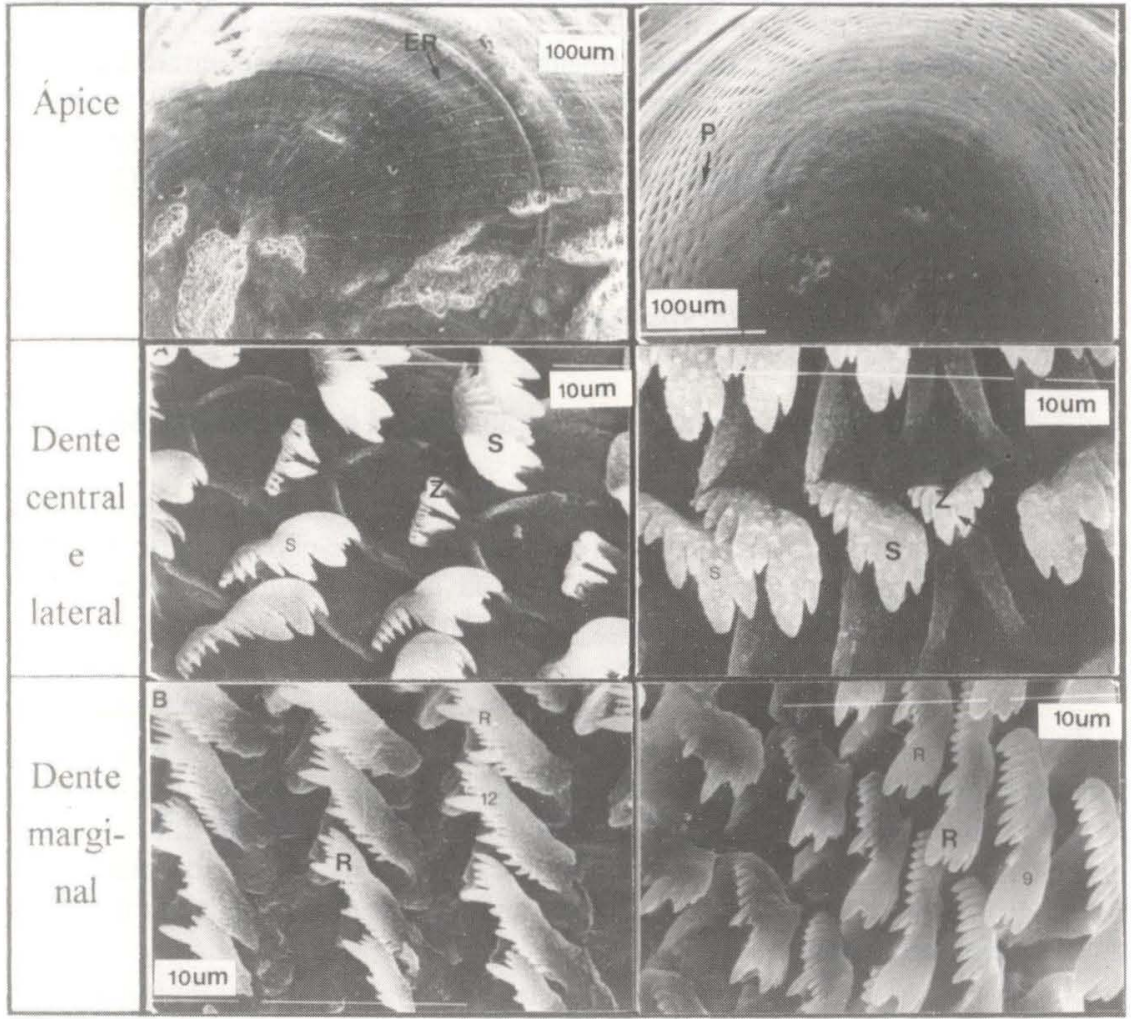

Fig. 29. Aspecto do ápice e da rádula ao microscópio eletrônico de varredura. F. gentilis, MCN 31009 -parátipo, ápice visto de cima, aumento 400x; dente raquidiano e laterais; dentes marginais; $B$. ingae, MCN 31036 - parátipo, ápice visto de cima; dente raquidiano e laterais, MCN 31036 - parátipo; dentes marginais, MCN 31021 - parátipo. (ER) Estrias radiais; (P) pontuaçōes; ( $\mathbf{Z})$ dente raquidiano; $(\mathbf{S})$ dente lateral; $(\mathbf{R})$ dente marginal; os números indicam a posição do dente na fileira.

Os índices $\mathrm{A} / \mathrm{C}$ e $\mathrm{A} / \mathrm{L}$ calculados a partir das medidas fornecidas por MARCUS \& MARCUS (1962) estão dentro da amplitude constatada para a amostra estudada (Figs 30-31). Os índices de G. ticaga são distintos de outras espécies de Gundlachia, mas assemelham-se aos de Burnupia ingae, embora esta última tenha a abertura da concha elíptica, enquanto em G. ticaga ela é arredondada (Figs 30-31). A pigmentação do manto lembra o padrão presente em $G$. concentrica.

HuBENDICK (1967) considera G. ticaga um sinônimo de G. obliqua. OHLWEILER \& LANZER (1993) discordam e revalidam a espécie.

Distribuição (Fig. 24). A descrição da espécie baseia-se em exemplares encontrados em aquário do Departamento de Zoologia da Universidade de São 
Paulo, não sendo designada uma localidade-tipo. Sua ocorrência é conhecida no presente para a Argentina, em Missiones e Corrientes (dois lotes MCT/PUC-RS) e Brasil, em Minas Gerais (se for confirmado que os Ancylidae encontrados com $G$. lutzi referem-se a G. ticaga), Paraná: Toledo (coleção IAP-Toledo) e Rio Grande do Sul: Torres, Tramandaí, Santo Antonio da Patrulha, Viamão, Gravataí, Rio Grande e Santa Vitória do Palmar (MCN 7366, MCN 7346, MCN 7506, MCN 7339, MCN 30221).

\section{Gundlachia bakeri Pilsbry, 1913}

Desta espécie só se conhece a descrição original e esparsas citações para a região amazônica.

Descrição. A diagnose da espécie baseia-se em uma forma septada e está caracterizada por uma concha pequena, oblonga, com ápice obtuso, muito próximo a extremidade posterior e sobrepondo a borda direita. Há linhas concêntricas próximo a concha embrionária e linhas radiais na parte anterior. O septo cobre $2 / 3$ da superfície ventral (PILSBRY 1913).

PILSBRY (1913) encontra junto a estas formas septadas outro Ancylidae, de concha sem septo, o qual ele está inclinado a acreditar que corresponde à forma não septada desta mesma espécie. Essa concha é descrita por ele como fina, transparente, oval, de ápice posterior, arredondado, voltado para a margem direita, com uma leve depressão dorsal e tendo a concha embrionária pontuada. A teleoconcha possui linhas de crescimento e linhas radiais diminutas e irregulares, iniciando no limite da concha embrionária.

Os poucos exemplares examinados de G. bakeri, procedente do Igarapé dos Peruanos, têm manto sem ou com pigmentação fraca, concentrada em uma mancha dorsal e outras esparsas próximo à margem do manto.

As áreas de inserção muscular anterior e posterior esquerdas são arredondadas e a anterior direita tem forma elíptica e é levemente mais extensa (Fig. 14).

A rádula não é conhecida.

Gundlachia bakeri é referida por HUBENDICK (1967) como sinônimo de $G$. obliqua. OHLWEILER \& LANZER (1993) revalidam a espécie.

As linhas radiais, de acordo com a figura de PILSBRY (1913: pl. XXVI, fig. 5 ), assemelham-se às de $G$. radiata, por mostrarem-se espaçadas e iniciarem além dos limites da concha embrionária. Gundlachia bakeri e G. radiata possuem ápice com pontuções, mas se distinguem pela forma da área de inserção muscular.

Distribuição (Fig. 24). A localidade-tipo é um lago artificial, em um parque, na cidade de Belém, Pará (PILSBRY 1913). Para este Estado a espécie é citada, ainda, para Thomé-assú, Alenque, Obidos e Fordlândia (HAAS 1949a,b, 1952). Na Amazônia ela é mencionada para lagos na região do Rio Tapajóz e Rio Paracuní, Rio Tarumã Mirím, afluente do Rio Negro (HAAS 1949b; IRMLER 1975) arroios na floresta amazônica (em água de pH em torno de 4,5)(FITTKAU 1981) e Igarapé dos Peruanos. 


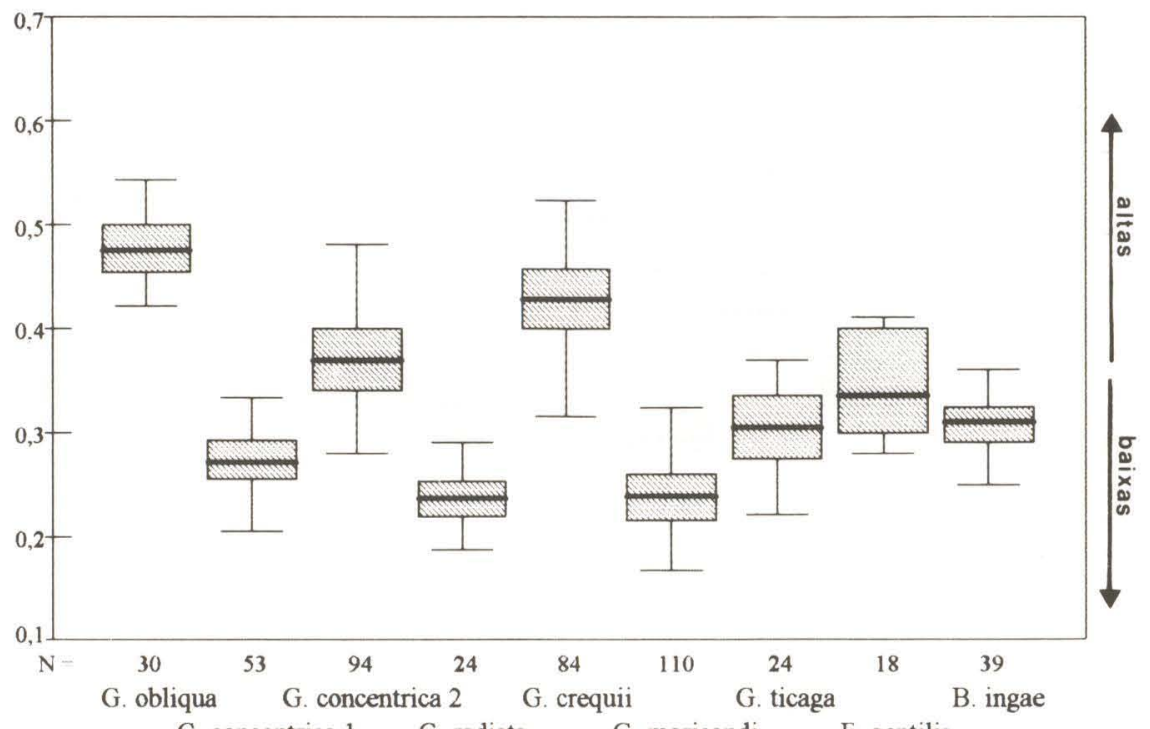

$\begin{array}{llll}\text { G. concentrica } 1 & \text { G. radiata } & \text { G. moricandi } & \text { F. gentilis }\end{array}$

Fig. 30. Índice da altura pelo comprimento $(A / C)$ de espécies de Ancylidae. A linha cheia é a nediana, a área hachurada corresponde a $50 \%$ dos casos e a amplitude os outros $50 \%$, sendo $25 \%$ acima e $25 \%$ abaixo da área em hachuras. Gundlachia concentrica 1 representa a amostra da Lagoa Jacaré e $G$. concentrica 2 de um açude, em Porto Alegre. O eixo dos $Y$ dá o valor dos índices e o dos $\mathrm{X}$ o tamanho da amostra $(\mathrm{N})$. As setas indicam a tendência da forma da concha.

\section{Gundlachia moricandi (Orbigny, 1837)}

Ancylus moricandi Orbigny, 1837: 355

Ancylus plaearius Bourguignat, 1862: 213

Ancylus aorus Bourguignat, 1862: 216

Ancylus lemoinei Ancey, 1901: 103

?Ancylus leucaspis Ancey, 1901: 103

Hebetancylus moricandi; Pilsbry, 1913: 671

Gundlachia nordenskiöeld Pilsbry, 1924: 57

Estudos da morfologia interna de G. moricandi são efetuados por HYLTONSCOTT (1953) e HuBENDICK (1964). A concha e a rádula ao MEV é analisada por LANZER $(1989,1995)$. O habitat é caracterizado por LANZER (1989).

Descrição. A espécie tem concha geralmente deprimida, com ápice pouco proeminente, obtuso, liso, localizado levemente a direita da linha mediana (Figs 4-5). A concha embrionária possue tênues linhas radias, partindo da região lisa do ápice e o restante da concha apresenta somente linhas de crescimento concêntricas (Fig. 28). Há grande variabilidade na forma da concha, com exemplares de concha mais estreita e alta (Fig. 6), dando ao ápice um aspecto distinto da forma mais típica. As extremidades da concha são levemente elevadas. 


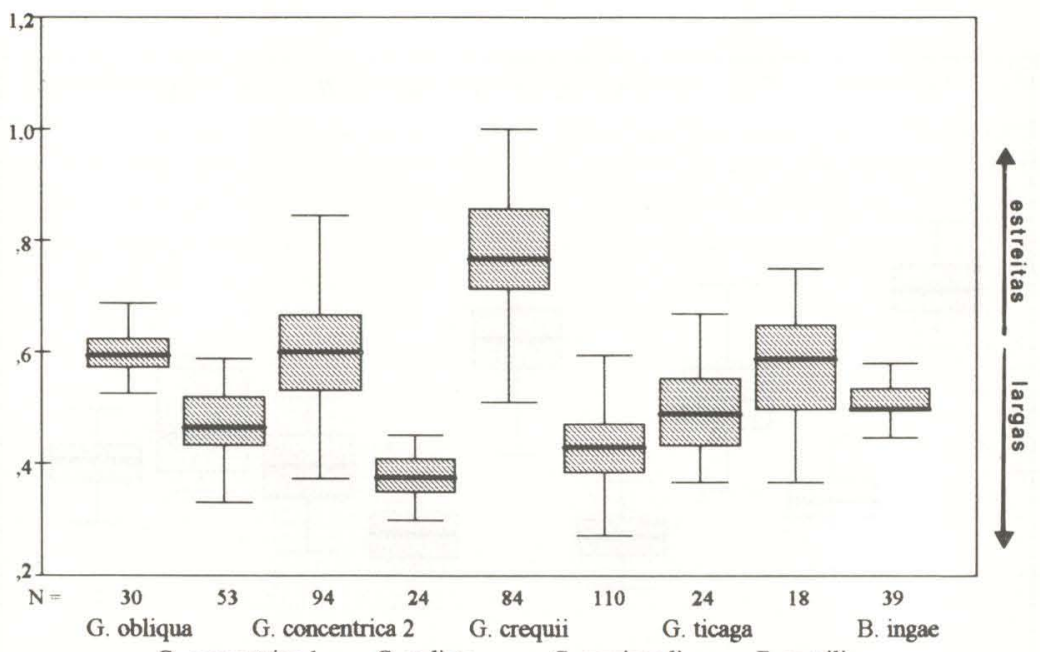

$\begin{array}{llll}\text { G. concentrica } 1 & \text { G. radiata } & \text { G. moricandi } & \text { F. gentilis }\end{array}$

Fig. 31. Índice da altura pela largura (A/L) de espécies de Ancylidae. A linha cheia é a mediana, a área hachurada corresponde a $50 \%$ dos casos e a amplitude os outros $50 \%$, sendo $25 \%$ acima e $25 \%$ abaixo da área em hachuras. Gundlachia concentrica 1 representa a amostra da Lagoa Jacaré e $G$. concentrica 2 a do açude em Porto Alegre. $O$ eixo dos $Y$ dá o valor dos índices e o dos $\mathrm{X}$ o tamanho da amostra $(\mathrm{N})$. As setas indicam a tendência da forma da concha.

A espécie pertence aos maiores Ancylidae, tendo o maior exemplar que se coletou $12,9 \mathrm{~mm}$ de comprimento, $6,7 \mathrm{~mm}$ de largura e $3 \mathrm{~mm}$ de altura.

O manto tem pigmentação desde fraca a regularmente acentuada, com coloração que varia do castanho escuro a acinzentado, quase preto. Uma lista pigmentada mais ou menos intensa inicia à direita da área de inserção muscular anterior direita e termina na borda palial posterior (HYLTON-SCOTT 1953). Esta lista geralmente de cor castanho é observada com grande freqüência nos exemplares coletados nas lagoas costeiras sulbrasileiras.

As três áreas de inserção muscular são de tamanho quase igual, sendo as duas anteriores amendoadas e o posterior arredondada (Fig. 16).

A rádula tem o dente raquidiano com as cúspides principais relativamente mais curtas que nas outras espécies. A cúspide principal direita é fina e bem mais curta que a esquerda, ambas tendo a cada lado, em geral, uma ou duas cúspides. Não há uma cúspide pequena entre elas. Os dentes laterais têm três cúspides curtas com uma pequena entre elas e duas outras pequenas ao lado da externa. Os dentes marginais têm de nove a 12 cúspides (Fig. 28).

A variação na morfologia da concha foi anteriormente constatada por CLESSIN (1882), WALKER (1925) e HAAS (1939) que escreve: "Esta espécie pode tomar duas formas: uma achatada, em forma de escudo, e outra elevada, comprimida lateralmente..." As duas formas podem ser encontradas juntas.

Gundlachia moricandi é uma espécie que se distingue facilmente de outras Gundlachia pela sua concha muito deprimida e seu ápice obtuso, liso. Constitui-se, ainda, na espécie mais comumente encontrada a leste dos Andes. 
Distribuição (Fig. 25). Citações de G. moricandi são feitas para a Venezuela (MARTENS 1873; HuBENDICK 1967), Brasil (WALKER 1925; HAAS 1939, 1949a,b; VAN BENTHEM-JUTTING 1943; LUCENA 1951; HUBENDICK 1964, 1967; IRMLER 1975; FERNANDEZ 1981; LANZER \& SCHÄFER 1985), Bolívia (NORDENSKIÖLD 1903), Paraguai (MARTENS 1895; HUBENDICK 1967; QuINTANA 1982), Argentina (ORBIGNY 1835-1846; HYLTON-SCOTT 1953; OlaZARRI 1978; FERNANDEZ 1981; DI PERSIA 1986; DI PERSIA \& OlaZARRI 1986) e Uruguai (BARATINI 1951; FIGUEIRAS 1964; HuBENDICK 1967; OlazARRI 1978,1983). No Brasil, as citações de HAAS (1939) para o Ceará, Paraíba, Pernambuco e Alagoas são confirmadas pelo exame dos lotes SMF 44351 a SMF 44364 e SMF 149748. De acordo com HAAS (1939) e VAN BENTHEM-JutTING (1943), G. moricandi é a espécie de Ancylidae mais comum no Nordeste brasileiro. Identificou-se como G. moricandi uma amostra procedente do Rio Candeias, Amazonas, coletada pela Equipe de Esquistossomose do INPA, podendo-se confirmar a ocorrência da espécie para a área. Para outros Estados ela é verificada para a Bahia (MZUSP), Paraná (coleção do IAP-Curitiba), Santa Catarina (MCT/PUC-RS 4034, MCT/PUC-RS 4155, MCT/PUC-RS 4137, Rio Grande do Sul (MCT/PUC-RS 3405, MCT/PUC-RS 3389, SMF 149277 a SMF 149279, SMF 293723, MZUSP 2651, MCN 4125, MCN 8982, MCN 8984, MCN 8995, MCN 9712). Os lotes MZUSP (Assunção), MZUSP 2649 e SMF 149276 confirmam sua ocorrência no Paraguai e o MLP 30601, na Argentina.

Nenhuma citação da espécie ou amostras depositadas em Museus foram encontradas para o Equador, Colombia, Guianas e Suriname. Uma vez que $G$. moricandi ocorre no norte da Venezuela, sua ausência nesses países deve-se com certeza aos escassos levantamentos dos moluscos feitos para estas áreas.

HAAS (1955) cita Hebetancylus sp. para o Lago Langui (4000m) nos Andes peruanos, em profundidade de $0-0,6 \mathrm{~m}$. Ele menciona que os três exemplares, mais ou menos danificados parecem ser uma espécie do grupo $H$. moricandi e fornece uma resumida descrição, sem figura. Encontrou-se na coleção do Museu Britânico, um exemplar identificado como Hebetancylus sp., procedente do Lago Langui e coletado em 24.VIII.1937. Ancylus lagunarum, descrito também em HAAS (1955), tem a espécie-tipo (BMNH - C.I.C. 1220/6) e o parátipo (SMF 163355) com datas de coleta em 5.IX.1937 e 3.IX.1937, respectivamente. Além desta proximidade nas datas de coleta com a de Hebetancylus sp. do Museu Britânico, a profundidade dada na etiqueta que acompanha esse material é $0,6 \mathrm{~m}$. Verifica-se que Hebetancylus sp. depositado no Museu Britânico não é G. moricandi. Entretanto, não se pode afirmar com certeza, se esse exemplar pertence ao material descrito por HAAS (1955) como Hebetancylus sp., permanecendo a dúvida quanto à ocorrência desta espécie nos Andes.

HuBENDICK (1967) diz que G. moricandi não é conhecida a oeste dos Andes, a menos que G. philippiana seja uma sinônimo desta espécie. Como referido anteriormente o material descrito como G. philippiana exige revisão. G. moricandi não foi encontrada ao sul do Rio Colorado, na Argentina e não sendo conhecida para o Chile nem para os Andes, parece estar limitada à região de clima tropical e subtropical. 


\section{Gundlachia concentrica (Orbigny, 1835)}

Ancylus concentricus Orbigny, 1835: 23, Orbigny, 1835-46: 354, pl XLII, figs 18-21

Ancylus culicoides Orbigny, 1835: 23, Orbigny, 1835-46: 355, pl.XLII, figs 9-12

Ancylus barilensis Moricand, 1845: 159, pl. V, figs 30-32

Ancylus plagioxus Bourguignat, 1862: 217

Ancylus concentricus bonariensis Strobel, 1874: 51, pl 2, fig. 4

Ancylus rushi Pilsbry, 1897: 298, pl. VI, figs 11-14

Ancylus uncinatus Ancey, 1897: 21

Velletia fuhrmanni Piaget, 1914: 267, pl.X, figs 13-15

Uncancylus amelilae Pilsbry, 1920: 9, fig. 4

Uncancylus calverti Pilsbry, 1920: 7, fig. 4

Ancylus patagonicus Biese, 1948: 235, fig. 12

Estudos de G. concentrica são efetuados por HubENDICK $(1964,1967)$, FERNANDEZ (1981) e LANZER \& VEITENHEIMER-MENDES (1985). A concha e a rádula ao MEV são descritas por BURCH (1974) e LANZER $(1989,1995)$. O habitat é discutido em LANZER \& VEITENHEIMER-MENDES (1985) e LANZER (1989).

Descrição. A espécie está caracterizada por uma concha tênue, transparente, ornamentada por finas linhas de crescimento e por linhas radiais sobre as quais pode haver pelos originados do perióstraco. Essas linhas eventualmente cobrem toda a concha. O ápice é agudo, recurvado para trás, com uma pequena área achatada dorsalmente e sua projeção vertical pode não alcançar a borda da concha, sobreporse a ela ou mesmo ultrapassá-la (Fig. 3). A concha embrionária apresenta uma banda de orifícios dispostos de forma desordenada, entre leves linhas radiais (Fig. 27).

O manto tem pigmentação esparsa e irregular, formando manchas de coloração escura, às vezes mais densa junto a região anterior do manto e no extremo posterior direito, inferior ao ápice.

A área de inserção muscular posterior esquerda é arredondada. As áreas de inserção muscular anteriores são alongadas transversalmente, sendo a direita mais estreita e mais longa que a esquerda (Fig. 15). Eventualmente as áreas de inserção muscular anteriores podem se unir na região mediana, através do epitélio adesivo.

A rádula tem o dente raquidiano com duas cúspides principais longas e afiladas, podendo haver uma cúspide pequena entre elas, e duas a três a cada lado. Os laterais têm as três cúspides maiores um pouco alongadas, com uma cúspide fina entre elas e uma a três, raramente quatro, lateralmente. Os dentes marginais têm, em geral, dez cúspides (Fig. 27).

Como em G. moricandi, a forma da concha é muito variada. MORICAND (1845) comenta que Ancylus barilensis é muito semelhante a A. concentricus, mas a diferencia pelo seu tamanho menor, pelo ápice mais excêntrico, mais saliente e pontiagudo, mas não recurvado. Ancylus barilensis e A. plagioxus têm como localidade-tipo o Lago Baril, na Bahia, Brasil. Ambas espécies são consideradas por HUBENDICK (1967) sinônimos de G. concentrica. CLESSIN (1882) fornece duas figuras de $A$. barilensis: a primeira, Estampa 2, figuras 23-26, assemelha-se à figura de MORICAND (1845); a segunda, Estampa 7, Fig. 9, apresenta aspecto distinto, com ápice não tão pontiagudo e estrias radiais ausentes. Da mesma forma as espécies de 
PILSBRY (1920), Uncancylus calverti e U. amelilae, sinônimos de G. concentrica (HuBENDICK 1967; FERNANDEZ 1981) são mais uma constatação da presença de conchas com formas distintas. PILSBRY (1920) menciona que embora $U$. amelilae lembre $U$. calverti, diferencia-se desta pelo tamanho menor, altura e largura maiores e pelo ápice muito próximo a margem direita. A variabilidade na morfologia da concha de $G$. concentrica é demonstrada nas figuras 30 e 31 , onde compara-se uma amostra procedente de um açude nos arredores de Porto Alegre (MCN 5201, MCN 5360, MCN 5617, MCN 5621, MCN 5701, MCN 5800) com as amotras da Lagoa Jacaré, extremo sul do Brasil. No açude, o maior exemplar não ultrapassa $8 \mathrm{~mm}$ de comprimento, enquanto na Lagoa Jacaré atinge até $11 \mathrm{~mm}$. Através dos índices evidencia-se que os exemplares do açude são mais altos e mais estreitos que os da Lagoa Jacaré. STROBEL (1874) cria a variedade G. concentrica bonariensis baseado no tamanho menor e na falta de estrias radiais na região anterior da concha. A forma é citada por WURTZ (1951) e FERNANDEZ (1981) em nível de subespécie. CAZZANIGA (manuscrito não publicado) considera injustificada esta denominação, uma vez que a morfologia da concha Gundlachia é muito variada e o conhecimento do grupo é insuficiente para que se estabeleça subespécies.

Na Lagoa Mangueira, localizada no extremo sul do Brasil, três exemplares coletados com a forma típica de $G$. concentrica têm concha estreita e alta, ápice muito proeminente, recurvado e com projeção ultrapassando a borda da concha e tendo linhas radiais na região anterior. Estes Ancylidae assemelham-se muito a Ancylus rushi (PILSBRY 1897: estampa VI, figs 11-14). HUBENDICK (1967) coloca A. rushi na lista de sinônimos de G. gayana (Orbigny, 1837), com uma interrogação, e cita-a também como sinônimo de G. concentrica. FERNANDEZ (1981) considera A. rushii sinônimo de $G$. concentrica. É possível que esses três exemplares da Lagoa Mangueira sejam uma variação extrema de $G$. concentrica, com a qual mostram semelhança quanto aos músculos e pigmentação do manto. Ainda que um ápice tão pronunciado nunca tenha sido observado em outras populações estudadas (LANZER \& VEITENHEIMER-MENDES 1985), concorda-se que $A$. rushi seja um sinônimo de G. concentrica.

Como já referido, $G$. concentrica assemelha-se a $G$. crequi quanto ao ápice agudo, a presença de estrias radiais com pelos periostracais e as áreas de inserção muscular anteriores alongadas, podendo se unir na região mediana (Figs 11, 15). Entretanto, essas espécies podem ser distinguidas pela sua conquiliometria: $G$. crequi é relativamente mais alta que $G$. concentrica; tem um achatamento lateral mais ou menos marcado que faz com que a projeção do ápice ultrapasse ou sobrepõnha-se, na maioria das vezes, a borda da concha (Figs 1, 3, 30, 31). Além disto, o padrão de pigmentação do manto e a rádula são distintos entre as duas espécies (Fig. 27).

Distribuição (Fig. 26). Gundlachia concentrica ocorre do norte da Costa Rica (PILsBRy 1920; HuBENDICK 1967; SMF 260912) até o limite de $46^{\circ} \mathrm{S}$ (HYLTON-SCOTT 1963), sendo provavelmente a espécie de ocorrência mais austral entre os Ancylidae sulamericanos. Na América do Sul, G. concentrica é referida para a Venezuela (Hubendick 1967), Colombia (PIAGET 1914), Equador (ORBIGNy 1835-1846), Peru (SMF 147510), Brasil (ORBIGNy 1835-1846; HAAS 1949b; 
KLEEREKOPER 1955; HubENDICK 1964, 1967; LANZER \& SCHÄFER 1985; LANZER \& VEINTENHEIMER-MENDES 1985; MZUSP 641, MZUSP 17138, MZUSP 17139 , MZUSP 7276, MZUSP 16172, MCT/PUC-RS 4113, MCT/PUC-RS 4086, MCT/PUC-RS 3994, MCT/PUC-RS 4240, MCT/PUC-RS 3386, MCT/PUC-RS -Pirapó e Rincão Vermelho, MCN 5800, SMF 149274, SMF 149275; Chile (HUBENDICK 1967 e BMNH - parátipo A. patagonicus), Argentina (STROBEL 1874; DOERING 1874; HYLTON-SCOTT 1963; CAZZANIGA 1981, MCT/PUC-RS - San Javier, MLP 2160, MLP 2153, IML 905, MACN 11835, MACN 14861), Bolívia (NoRDENSKIÖLD 1903), Paraguai (QUINTANA 1982; MZUSP 2649, SMF 149281 , SMF 203710) e Uruguai (BARATINI 1951; FigueIras 1964; Di PERSIA \& OLAZZARI 1986, MNRJ 2678, MNHNM 5628, MNHNM 5627, MNHNM 5636).

VAN DER Schalie (1948) cita a espécie para Porto Rico. Entretanto, nem a vaga descrição feita que menciona uma concha relativamente robusta, com proeminentes estriações, nem a figura apresentada (VAN DER SCHALIE 1948: Estampa 9, Fig. 9) representam G. concentrica. HARRY \& HUBENDICK (1964) afirmam ser esta $G$. radiata, com o que se concorda.

O único registro desta espécie para a Bolívia é talvez o de NORDENSKIÖLD (1903) referindo-se a exemplares encontrados junto a formas septadas de $G$. moricandi no Chaco. NORDENSKIÖLD (1903) diz que esses exemplares são mais raros que $G$. moricandi e assemelham-se mais a $A$. concentricus, embora devam pertencer a espécie do norte argentino, A. uncinatus, ambas consideradas por HuBENDICK (1967) sinônimos de G. concentrica.

As citações de $G$. concentrica para o norte e nordeste do Brasil exigem revisão. HAAS (1939) cita a espécie para Pernambuco, mencionando os lotes SMF 4451 e SMF 44352, os quais examinou-se, constatando não serem $G$. concentrica. VAN BENTHEM-JutTING (1943) cita Protancylus (Uncancylus) barilensis (Moricand) para o Rio Grande do Norte, a partir de um único exemplar, do qual não há descrição nem figura. HAAS (1949a,b, 1952) cita para região amazônica espécies que são consideradas por HUBENDICK (1967) sinônimos de G. concentrica. As localidades referidas por HAAS (1949a,b, 1952) são: o rio Acará-Pequeno, junto a Tomé-assú, curso inferior do rio Tapajóz, próximo a Fordlândia e Santarém e para afluentes do Amazonas, nas proximidades de Obidos, no Pará e baixo Solimões e para o Rio Madeira, no Amazonas. IRMLER (1975) menciona, também, Uncancylus c.f barilensis (Moricand) para o rio Tarumã Mirim na bacia amazônica. Estas referências precisam ser verificadas.

A única citação da espécie para a Bahia é referente ao Lago Baril, um lago artificial na cidade de Salvador (MORICAND 1845). De acordo com PARAENSE (1986), o Lago Baril é hoje denominado Dique de Tororó e nenhum Ancylidae foi encontrado por ele, nem pela autora, em visita ao local em setembro de 1987.

É possível que $G$. concentrica mostre preferência ao clima subtropical e frio, chegando até a Costa Rica através dos Andes, sendo mais rara na região tropical. 


\section{Ferrissia Walker, 1903}

A característica genérica de Ferrissia é a fina escultura radial, microscópica no ápice (WALKER 1903, 1924; BASCH 1963; HARRY \& HUBENDICK 1964; HUBENDICK 1964, 1970; BROWN 1980).

De acordo com ZILCH (1959/1960), Ferrissia tem representantes fósseis desde o Eoceno na América do Norte, Europa e norte da Africa. O gênero é registrado também como fóssil do Holoceno da Holanda, demonstrando que seu estabelecimento naquela área não é tão recente (VAN DER VELDE \& HADDERINGH 1981). Este registro constitui-se, provavelmente, no limite norte de distribuição do gênero na Europa.

BASCH (1963) diz que Ferrissia é o gênero mais complexo de todos os Ancylidae e pode ser o Gastropoda de distribuição mais ampla. Espécies são conhecidas para a América do Norte (WURTZ 1951; BASCH 1963), Europa (VAN DER Velde \& Hadderingh 1981; CAstagnolo et al. 1982), Asia (Hubendick 1970; BRANDT 1974), América Central (WURTz 1951; HARRY \& HUBENDICK 1964; HUBENDICK 1967; HARrison 1983), Africa (WALKER 1924; BROWN 1980) e Austrália (HUBENDICK 1967).

PILSBRy (1924) e KLEEREKOPER (1955) mencionam o gênero para a América do Sul, sem denominar nenhuma espécie. LANZER (1991) descreve F. gentilis, habitando lagoas do sul de Santa Catarina até a barra da Laguna dos Patos, no Rio Grande do Sul.

A distribuição de Ferrissia na América do Sul é desconhecida.

\section{Ferrissia gentilis Lanzer, 1991}

LANZER (1991) descreve a espécie incluindo caracteres da concha e rádula analisados ao MEV e fornece sua distribuição na região costeira do sul do Brasil. Aspectos do habitat são dados por LANZER (1989).

Descrição. A concha é pequena, alta, com ápice arredondado, levemente à direita da linha mediana, não recurvado, com achatamento dorsal e com linhas radiais microscópicas, espaçadas, partindo do centro do ápice (Figs 7, 8, 29). A teleoconcha tem linhas de crescimento finas geralmente bem marcadas e sem escultura radial.

O maior exemplar estudado mede $3,2 \mathrm{~mm}$ de comprimento, $2 \mathrm{~mm}$ de largura e 1,3mm de altura (MCN 31008 -holótipo).

$\mathrm{O}$ manto não tem pigmentação.

As áreas de inserção muscular são pequenas, sendo a anterior e posterior esquerda arredondadas e a anterior direita um pouco alongada transversalmente (Fig. 18).

A conquiliometria é mostrada nas figuras 30 e 31 .

$\mathrm{O}$ dente raquidiano tem base larga, com duas cúspides principais simétricas e geralmente duas a três, ou raramente quatro cúspides pequenas entre elas e três a quatro lateralmente. Os primeiros dentes laterais têm uma ou duas cúspides pequenas entre a mediana e a interna e uma entre a mediana e a externa. Os dentes marginais possuem até 15 cúspides (Fig. 29). 
As linhas radiais no ápice de $F$. gentilis só podem ser observadas ao MEV em aumento a partir de 200x. São tênues e espaçadas, diferindo daquelas das outras espécies citadas que, ao MEV, aparecem muito marcadas e próximas umas das outras e, consequentemente, em maior número (BURCH 1974; BROWN 1980; HARRISON 1983; LANZER 1989). A ausência de pigmentação sobre o manto é uma característica encontrada também em $F$. modesta (Crosse, 1880), F. australica (Tate, 1880) e $F$. tenuis (Bourguignat, 1862). As áreas de inserção muscular assemelham-se a outras espécies. $\mathrm{O}$ dente raquidiano de $F$. gentilis distingue-se daquele de $F$. wautieri (Mirolli, 1960) e de $F$. irrorata (Guilding, 1828) porque o destas espécies possuem somente uma pequena cúspide entre as principais (CASTAGNOLO et al. 1982; HARRISON 1983). Os dentes da rádula de $F$. gentilis apresentam um número de cúspides também maior que nas outras espécies do gênero estudadas por CASTAGNOLO et al. (1982) e HARRISON (1983), que analisaram as rádulas ao $\mathrm{MEV}$.

Distribuição. A espécie é conhecida para Santa Catarina: Sombrio (MCN 31008, MCN 31009, 31012) e Rio Grande do Sul: Torres (MCN 31017 e MCN 31018), Capão da Canoa (MCN 31016), Tramandaí (MCN 31010, MCN 31011, MCN 31019, SMF 307485, SMF 307486), Gravataí (MCN 7339) e Mostardas (MCN 31015).

Uma segunda espécie, não determinada, apresentando linhas radiais típicas sobre o ápice e na região anterior da teleoconcha é registrada para o Rio Grande do Sul: Torres: Rio do Forno, São Borja: Rio Uruguai (MCT/PUC-RS), Santa Catarina: Campos Novos: Rio Canoas (MCT/PUC-RS 4079).

\section{Burnupia Walker, 1912}

Burnupia é conhecida para o continente africano, com cerca de 20 espécies e subespécies descritas. Segundo BROWN (1980) o gênero não foi registrado a oeste dos Lagos Edward, Kivu e Tanganica, embora esteja presente no sudeste do Zaire e norte de Angola. Esta região de lagos constitui-se no limite norte do gênero na África (VAN DAME 1984).

A presença de pontuações dispostas radialmente sobre a concha embrionária é uma característica genérica (WALKER 1912, 1924; OBERHOLZER \& VAN EEDEN 1969; BROWN 1980).

Nada se sabe a respeito da origem e distribuição de Burnupia na América do Sul. Exemplo semelhante de ocorrência nos continentes sul-americano e africano são fornecidos por Biomphalaria Preston, 1910 e Eupera Bourguignat, 1854. Estas relações zoogeográficas não têm sido explicadas.

\section{Burnupia ingae Lanzer, 1991}

A diagnose de $B$. ingae inclue caracteres da concha e rádula ao MEV. LANZER (1991) fornece a ocorrência da espécie na Planície Costeira do Rio Grande do Sul. O habitat está descrito em LANZER (1989). 
Descrição. A concha é pequena, frágil, com ápice arredondado, não recurvado, com extremidade plana (Figs 9-10). A concha embrionária possui uma banda de pontuações dispostas em linhas radiais (Fig. 29). A teleoconcha tem linhas radiais curvadas que podem vir a cobrir toda a concha. Em alguns exemplares, sobre estas linhas radiais há protuberâncias arredondadas do perióstraco.

A concha raramente ultrapassa $2,5 \mathrm{~mm}$ de comprimento e o maior exemplar coletado mede $3,0 \mathrm{~mm}$ de comprimento, $1,9 \mathrm{~mm}$ de largura e $0,8 \mathrm{~mm}$ de altura (MCN 31034).

O manto não tem qualquer pigmentação.

A área de inserção muscular anterior direita é alongada para trás, paralelamente a borda do manto, a anterior esquerda é arredondada e a posterior esquerda alongada (Fig. 19).

A rádula tem o dente raquidiano levemente assimétrico, com duas cúspides principais e uma menor entre elas e duas a quatro a cada lado. Os dentes laterais têm a cúspide mediana maior, com uma ou duas cúspides entre as outras duas e três a quatro lateralmente a externa. Os dentes marginais são alongados, com quatro a sete cúspides lateralmente a cúspide externa (Fig. 29).

As relações A/C e A/L são apresentadas nas figuras 30 e 31 .

Em $B$. ingae as pontuações da concha embrionária não atingem o centro do ápice, diferindo do figurado por BURCH (1974) e BROWN (1980) para B. capensis Walker, 1924 e Burnupia sp., respectivamente. A presença de linhas radiais é mencionada para outras espécies como B. caffra (Krauss, 1848) e B. mooiensis (Walker, 1923) (WALKER 1924; OBERHOLZER \& VAN EEDEN 1969). A disposição curvada das linhas radiais é encontrada também no gênero Gundlachia, em $G$. bakeri. Entretanto, nesta última, as pontuações sobre o ápice são desordenadas. BROWN (1961) cita um padrão irregular de nódulos sobre a concha de Burnupia sp. cf. caffra, mas sem referí-los como estruturas do perióstraco. O manto de $B$. mooiensis apresenta grânulos pretos distribuídos sobre sua superfície e mais densamente concentrados ao redor das áreas de inserção muscular (OBERHOLZER \& VAN EEDEN 1969). Tanto BROWN (1961), estudando Burnupia sp. cf. caffra, quanto WRIGTH (1963), estudando Burnupia sp. cf. gordonensis (Melvill \& Ponsonby, 1903), não fazem qualquer referência à pigmentação do manto.

A inserção muscular anterior direita parece ser o caráter que melhor distingue B. ingae de outras espécies, onde esta área de inserção muscular é pouco alongada.

Comparando os índices constatados por WRIGTH (1963) para Burnupia sp. cf. gordonensis, os obtidos de Brown (1961) para Burnupia sp. cf. caffra, aos índices obtidos para B. ingae por LANZER (1991), verifica-se que esta última espécie diferencia-se da primeira por apresentar uma concha mais estreita, e da segunda por ser menos elevada. Em relação às espécies sul-americanas sua conquiliometria, como já referido, mostra semelhança à de G. ticaga (Figs 30-31).

Distribuição. Burnupia ingae foi registrada para Santa Catarina: entre Campos Novos e Anita Garibaldi (MCT/PUC-RS 4091), Sombrio (MCN 31020 holótipo, MCN 31021 e SMF 307481) e Rio Grande do Sul: Torres (SMF 307482 e SMF 307283), Viamão (MCN 31034), Osório (MCN 31022), Tramandaí (MCN 
31014, SMF 307484, MCN 31023, MCN 31025), Gravataí (MCN 31024), Cidreira (MCN 31026, MCN 31035), Palmares do Sul (MCN 31027- MCN 31030), Mostardas (MCN 31031, MCN 31036) e São José do Norte (MCN 31032 e MCN 31033).

\section{Laevapex Walker, 1903}

O gênero está representado na América do Norte por L. fuscus (Adams, 1841) e L. diaphanus (Haldeman, 1841), distribuindo-se até o sul do Canadá (BASCH 1963). Laevapex é registrado pela primeira vez para América do Sul por SANTOS (1989).

\section{Laevapex vazi Santos, 1989}

Descrição. A concha é pequena, fina e de coloração marron claro, apresentando linhas de crescimento concentricas e finas. Em um exemplar, foi observado também uma escultura radial extremamente fina. O ápice é arredondado, liso, inclinado para a direita, atingindo a borda da concha ou ultrapassando-a. 1989).

A pigmentação do manto está concentrada sobre seu lado esquerdo (SANTOS

A área de inserção muscular esquerda é arredondada, a anterior direita é elíptica e maior que a esquerda a qual tem forma amendoada (SANTOS 1989) (Fig. 20).

Os índices fornecidos por SANTOS (1989) são: $\mathrm{A} / \mathrm{C}=0,50-0,61(\overline{\mathrm{x}}=0,55) \mathrm{e}$ $\mathrm{A} / \mathrm{L}=0,33-0,40(\overline{\mathrm{x}}=0,35)$. Esta autora comenta que a concha de $L$. vazi difere das espécies norte-americanas do mesmo gênero, as quais tem ápice obtuso e sempre na linha mediana da concha e afirma que a concha de $L$. vazi lembra aquelas de Gundlachia obliqua e G. concentrica.

$\mathrm{Na}$ rádula, o dente raquidiano é quadricúspide com a cúspide principal esquerda maior que a direita. Os dois primeiros dentes laterais têm três cúspides, aumentando o número de cúspides e diminuindo o tamanho do dente em direção à extremidade da fileira (SANTOS 1989).

Distribuição. Laevapex vazi é citada para Ourinhos, São Paulo, Brasil.

\section{Laevapex sp.}

Em material procedente do Rio Ocoí, recebido do setor de Limnologia do IAP, encontrou-se exemplares de Laevapex os quais são distintos de L. vazi. Esses exemplares têm concha amarelo pálido, translúcida, marcada por leves linhas de crescimento e com linhas radiais quase imperceptíveis. $O$ ápice é liso, bem posterior, mediano, obtuso, com área dorsal plana.

O manto tem uma pigmentação cinza escuro a preta, homogênea na região dorsal e tornando-se esparsa e mais escura em direção à borda. Essa pigmentação está ausente somente sobre as áreas de inserção muscular, onde há grânulos escuros, e na borda do manto. 
As áreas de inserção muscular anteriores estão unidas na região mediana e são mais ou menos riniformes. A área de inserção direita é levemente maior que a esquerda. Ambas são recurvadas para a região posterior. A área de inserção muscular posterior é grande, maior que as anteriores e não localiza-se a esquerda, como é comum em Ancylidae, mas estende-se transversalmente, na região mediana, inferior ao ápice (Fig. 21).

Laevapex sp. tem concha, áreas de inserção muscular e pigmentação diferentes daqueles em L. vazi, assemelhando-se mais aos de L. fuscus. Distiguem-se desta última pelas áreas de inserção muscular, especialmente pela posterior, onde em L. fuscus ela é menor que as anteriores e estende-se levemente para esquerda da linha mediana.

Além da citação anterior para o Paraná, registra-se esta espécie, também, para o Rio Grande do Sul: Itá, rio Uruguai (MCT/PUC-RS 4232).

AGRADECIMENTOS. Às diversas instituições pela possibilidade de exame do material colecionado, ao CNPq (Conselho Nacional de Pesquisas) e DAAD (Deutscher Akademischer Austauschdienst) pelas bolsas concedidas, durante o período deste estudo.

\section{REFERÊNCIAS BIBLIOGRÁFICAS}

Aguayo, C.G. 1938. Los moluscos fluviatilis cubanos. Mem. Soc. Cubana Hist. Nat. 12 (3): 203-242.

1946. Gundlachia y Hebetancylus en Cuba. Rev. Soc. Malac. "Carlos de La Torre" 4 (2): 55-62.

1966. Una lista de los moluscos terestres y fluviatilis de Puerto Rico. Stahlia (5): 89-105.

ANCEY, M.C.F. 1897. Viaggio del Dott. Borelli nel chaco boliviano e nella República Argentina XI: Resultats malacologiques. Bol. Mus. Zool. Comp. Torino 12 (309): 1-22.

BÁNÀRESCU, P. 1992. Zoogeography of fresh waters. Distribution and Dispersal of Freshwater Animals. Wiesbaden, Aula, vol. 2, $511 \mathrm{p}$.

BARATINI, L.P. 1951. Enumeracion sistemática de los moluscos del Uruguay.

Publnes. cient. Serv. ocenaogr. Pesca, Montevideo, (6): 193-293.

BASCH, P.F. 1963. A review of the recent freshwater limpet snails of North America (Mollusca: Pulmonata). Bull. Mus. compar. Zool. 129 (8): 400-461.

Bavay, A. 1904. Mission de Crèqui-Montfort et Sénéchal de la Grange en Amérique du Sud. Mollusques terrestres et fluviatiles récoltés par le Dr. NeveuLemaire. Bull. Soc. zool. France 29: 152-156.

BIESE, W.A. 1948. Revisión de los moluscos terrestres y de agua dulce de concha de Chile. Bol. Mus. Nac. Hist. Nat. Chile 24: 217-239.

Boss, K.J. 1978. On the evolution of gastropods in ancient lakes, p.385-428. In: V.

Fretter. \& J. Peake (Eds). Pulmonates. Systematics, Evolution and Ecology. New York and London, Academic Press, vol. 2A, 540p.

Bourguignat, J.R. 1853. Catalogue des espèces du genre Ancylus. J. Conch. 4: 
169-199. $210-263$

1862. Les specileges malacologiques. Paris, Bailliers et Fils. p.79-82,

BRANDT, R.A.M. 1974. The non-marine aquatic Mollusca of Thailand. Arch. Moll. 105 (I-IV): 1-423.

BRown, D.S. 1961. A description of Burnupia sp cf. caffra (Krauss) (Gastropoda, Ancylidae) from Ethiopia. Ann. Mag. nat. Hist. 4 (42): 377-382.

1980. Freshwater snails of Africa and their medical importance. London, Taylor and Francis, IX $+487 \mathrm{p}$.

Burch, J.B. 1962. Notes on classification of freshwater limpets. Ann. Rep. Amer. Malac. Un. 29: 8-9.

1965. Cytotaxonomic studies of freshwater limpets (Gastropoda: Basommatophora). III. Japanese Ferrissia and Gundlachia. Malacologia 2 (2): 253-258.

1974. Relationships of Eurasian-North Africa Ancylus to the North American Rhodacmea (Pulmonate) as shown by apical shell sculpture. Malac. Rev. 7 (2): 127-132.

BurCH, J.B. \& P.T. LOVERDE. 1974. Apical shellsculpture of some North American freshwater limpets (Gastropoda: Basommatophora). Occ. Pap. Moll. 4 (50): 39-49.

Castagnollo, L.; G. Manganelli; F. Giusti. 1982. Ferrissia wautieri (Mirolli) (Mollusca: Pulmonata) nella val di Farma (Siena-Grosseto: Italia Centrale). Bol. Malacol. 18 (1/2): 267-284.

CAZZANIGA, N.J. 1981. Caracterización química y faunística de canales de drenaje del valle inferior del Río Colorado (partido de Villarino y Patagones, Província de Buenos Aires). Ecosur 8 (15): 25-46.

Clessin, S. 1882. Die Familien der Ancylinen. In: MARTINI \& CHEMINITz (Eds).

Syst. Conch. Cab. 1 (6). Nurnberg, Bauer \& Raspe, 80p.

Crosse, H. 1891. Faune malacologique terrestre et fluviatile de l' ile de SaintDomingue. J. Conch. 39: 69-211.

DI PERSIA, D.H. 1986. Zoobenthos of the Paraná system. p. 598-598. In: B.R. DAvies \& K.F. WALKeR (Eds). The ecology fo Rivers System. Drodrecht, Junk Publishers, XVIII+793p.

Di Persia, D.H. \& J. OlazArRI. 1986. Zoobenthos of the Uruguay system. p.623629. In: B.R. DAVIES \& K.F. WALKER (eds). The ecology of Rivers System. Drodrecht, Junk Publishers, XVIII+793p.

DOERING, A. 1874. Molluscorum terrestrium et fluviatilium fauna argentinae.

Period. zool. 1: 71-73.

FERNANDEZ, D. 1981. Mollusca Gasteropoda Ancylidae, p.101-114. In: R.A.

Ringuelet (Ed.). Fauna de Agua Dulce de la República Argentina 15 (7).

Figueiras, A. 1964. La malacofauna dulceaquícola del Uruguay (Parte I). Com.

Soc. Malac. Urug. 1 (7): 161-202.

FitTKAU, E.J. 1981. Armut in der Vielfalt-Amazonien als Lebensraum für Weichtiere. Mitt. Zoo. Ges. Braunau 3 (13/15): 329-342. 
Goodrich, C. \& H. VAN DER Schalie. 1937. Mollusca of Péten and North Alta Vera Paz, Guatemala. Misc. Publ. Mus. Zool. Univ. Mich. 34: 1-50.

GUYARD, A. \& J.P. POINTIER. 1979. Faune malacologique dulçaquicole et vecteurs de la Schistosomose intestinale en Martinique. Ann. Parasitol. Hum. Comp. 54 (2): 193-205.

HAAS, F. 1939. Zur Kenntnis der Binnen-Mollusken No-Brasiliens. Senckenbergiana 21 (1/6): 254-278.

1949a. Land und Süsswassermollusken aus dem Amazonas-Gebiete. Arch. Moll. 78 (4/6): 149-156.

1949b. On fresh water Mollusks from the Amazonian region. An. Inst. Biol. Mex. 20: 301-314.

1952. South American non-marine shells: further remarks and description. Fieldiana Zool. 34 (9): 107-132.

1955. Reports of Percy Slade Expedition to Lake Titicaca in 1937. XVII. Mollusca: Gastrapoda. Trans. Linn. Soc. London 1 (3): 283-308.

HARRISON, A.D. 1983. Identity of Ferrissia irrorata and Gundlachia radiata, Guilding's species of Ancylidae from St. Vicent, W. I. (Gastropoda: Pulmonata).

Arch. Moll. 113 (1/6): 7-15.

HARRY, H.W. \& B. HubENDiCK. 1964. The freshwater pulmonate Mollusca of

Puerto Rico. Medd. Göteborgs mus. Zool. Avd. 136: 1-73.

Hubendick, B. 1955. The anatomy of the Gastropoda. The Percy Sladen Trust

Expedition to Lake Titicaca. Trans. Linn. Soc. London, ser. 3, 1 (3): 309-327.

1964. Studies on Ancylidae: the subgroups. Medd. Göteborgs Mus.

Zool. Avd. 137: 1-72.

1967. Studies on Ancylidae. The Australian, Pacific and Neotropical

formgroups. Acta R. Soc. sci. litt. Gothoburg. zool. 1: 5-52.

1970. Studies on Ancylidae. The Paleartic and Oriental species and

formgroups. Acta R. Soc. sci. litt. Gothoburg. zool. 5: 1-52.

Hylton-ScotT, M.I. 1953. Notas sobre morfologia de Gundlachia Pfr. (Ancylidae) Mol. Pulm.). Physis 20 (59): 467-473.

1963. Moluscos terrestres y de agua dulce de la Patagonia, p.385-398. In:

C.D. Debouteville \& E. Rapport (Eds). Biologie de l'Amerique Australe. Paris, Cent. Nat. Rec. Scient, vol. 2.

IRMLER, U. 1975. Ecological studies of aquatic soil invertebrates in three inundation forests of Central-Amazonia. Amazoniana 5: 337-409.

KLEEREKOPER, H. 1955. Limnological observations in northeastern Rio Grande do Sul, Brazil. Arch. Hydrobiol. 50 (3/4): 553-567.

LANZER, R.M. 1989. Verbreitungsbestimmende Faktoren und Systematik südbrasilianischer Süsswassermollusken. Tese de Doutorado, não publicada, Instituto de Biogeografia, Universidade do Saarland, Saabrücken, II+331p.

1990. Rasterelektronenmikroskopische Untersuchungen an Gundlachia crequi (Bavay, 1904) (Basommatophora: Ancylidae). Arch. Moll. 119 (4/6): 205-217.

1991. Duas novas espécies de Ancylidae (Gastropoda: Basommatophora) 
para o sul do Brasil. Rev. Brasil. Biol. 51 (4): 703-719.

. 1995. Estudo dos Ancylidae Sulamericanos (Pulmonata: Basommatophora) Rádula ao Microscópio Eletrônico de Varredura. Biociências, Porto Alegre, 2 (2): 25-38.

LANZER, R.M. \& A. SCHÄFER. 1985. Padrões de distribuição de moluscos dulceaquícolas como indicadores de condições tróficas em lagoas costeiras do sul do Brasil. Rev. Brasil. Biol. 45 (4): 535-545.

LANZER, R.M. \& I.L. VEITENHEIMER-MENDES. 1985. Aspectos morfológicos e biológicos de uma população de Gundlachia concentrica (Orbigny, 1835) (Mollusca, Ancylidae) de um açude do sul do Brasil. Iheringia, Zool. 65: 41-56.

LucenA, D.T. 1951. Lista de moluscos do Nordeste brasileiro, com um apêndice sobre algumas espécies de outras regiões. Papéis Avulsos Dep. Zool. São Paulo 10 (3): 93-104.

MALEK, E.A. 1986. Freshwater and terrestrial snails of Saint Lucia, West Indies. Nautilus 100 (4): 143-147.

MARTENS, E. VON. 1873. Die Binnenmollusken Venezuela's. Ges. naturforschender Freunde zu Berlin, p.157-225.

1895. Mollusken von Paraguay. Ges. naturforschender Freunde zu Berlin 1895: 33-35.

Marcus, E. \& E. Marcus. 1962. On Uncancylus ticagus. Bol. Fac. Ciên. Letr. Univ. S. Paulo Zool. 261 (24): 217-245.

MoRICAND, S. 1845. Troisiéme Supplément au Mémoire sur les coquiles terrestre et fluviatiles de la province de Bahia. Mém. Soc. Phys. Hist. nat. Genève XI: 537-544.

NODENSKIÖLD, E. VON. 1903. Über die Trockenzeitanpassung eines Ancylus von Südamerika. Zool. Anz. 26: 590-593.

OBerholzer, G. \& J.A. VAN EEDEN. 1969. Studies on the morphology and histology of Burnupia mooiensis (Walker) (Mollusca, Basommatophora, Ancylidae). Wetensk. Bydr. Potchefstroom Univ. 7: 1-69.

OHLWEILER, F.P. \& R.M. LANZER. 1993. Morfologia da concha, rádula e madíbula de Gundlachia obliqua (Broderip \& Sowerby, 1832) como uma contribuição à sistemática de Ancylidae (Mollusca; Basommatophora). Biociências, Porto Alegre, 1 (1): 121-149.

- 1994. Morfologia de Gundlachia obliqua (Broderip \& Sowerby, 1832) (Mollusca, Gastropoda, Ancylidae). Iheringia, Zool. 77: 113-127.

OlAZARRI, J. 1978. Observaciones sobre biologia y ecologia de Biomphalaria (Moll. Gastropoda) en la zona de Salto Grande. 5 RDA 7.3: 1-49.

1983. Biomphalaria tenagophila (d'Orbigny, 1835)(Moll. Gastr.) en la zona de Salto Grande. IV. Fauna de posible relacion com sus poblaciones. Com. Soc. Malac. Urug. 6 (45): 131-163.

D'OrbignY, A.D. 1835-1846. Voyage dans l'Amérique méridionale. Paris, Bertrand, t. 5, part. 3, p.353-357.

PARAENSE, W.L. 1986. Lymnaea columella: two new Brazilian localities in the States of Amazonas and Bahia. Mem. Inst. Oswaldo Cruz 81 (1): 121-124. 
Parodiz, J.J. 1969. The Terciary non-marine Mollusca of South America. Ann. Carneg. Mus. 40: 1-241.

PfeIfFER, L. 1852. Bemerkungen über Gundlachia, Latia und Ancylus. Z. Malakozool. (9): 179-184.

PHILIPPI, R.A. 1866. Diagnosen einiger neuer Arten. Malakozool. BI. 13: 38-40. Piaget, J. 1914. Quelques Mollusques de Colombie. Mém. Soc. Sci. nat. Neuchâtel 5: 267.

PILSBRY, H.A. 1897. New species of molluks from Uruguay. Proc. Acad. Nat. Sci. Philad. 49: 290-298.

1913. Appendix: Notes on Gundlachia. Proc. Acad. Nat Sci. Philad. 65: 668-672.

1920. Costa Rican land and freshwater mollusks. Proc. Acad. Nat. Sci. Philad. 72: 2-10.

1924. South American land and freshwater mollusks: notes and descriptions. II South American genera of Ancylidae. Proc. Acad. Nat. Sci. Philad. 76: 49-61.

PoINTIER, J.P. 1976. Repartition locale et biogeographie des mollusques dulçaquicoles de la Guadeloupe (Antilles Françaises). Malac. Rev. 9 (1/2): 85-103.

QuinTANA, M.G. 1982. Catálogo preliminar de la malacofauna del Paraguay. Revta

Mus. argent. Cienc. nat. Bernardino Rivadavia Inst. nac. Invest. Cienc. nat. 11(3): 61-148.

SANTOS, S.B. 1989. On the morphology of Laevapex vazi n.sp. from Brazil (Mollusca: Pulmonata: Basommatophora: Ancylidae). Mem. Inst. Oswaldo Cruz 84 (Supl. IV): 467-473.

SMITH, E.A. 1895. A list of land and freshwater Mollusca of Trinidad. J. Conch. 8: $231-245$.

STROBEL, P. 1874. Materiali per una Malacostatica di terra e di acqua dolce dell' Argentina méridionale. Bibl. Malac. 4: 42-59.

VAN BENTHEM-JuTTING, W.S.S. 1943. Über eine Sammlung nichtmariner Mollusken aus dem niederschlagsarmen Gebiete Nordost-Brasiliens. Arch. Hydrobiol. 39: 458-489.

VAN DAMME, D. 1984. The freshwater Mollusca of northern Africa. Distribution, biogeography and palaeoecology. Developments in Hydrobiology 25. Drodrecht, Junk Publishers, VIII+164p.

VAn DeR Schalie, H. 1948. The land and fresh-water mollusks of Puerto Rico.

Misc. Publ. Mus. Zool. Univ. Mich. (70): 1-134.

VAN DER Velde, G. \& R.H. HadderIngH. 1981. De verspreiding van Ferrissia wantieri (Mirolli) (Gastropoda, Ancylidae) in Nederland. Basteria 45: 60-65.

WALKER, B. 1903. Notes on eastern american ancyli. Nautilus 17 (3): 25-31. 1912. A revision of the Ancyli of South Africa. Nautilus 25 (12): 139-144. 1924. The Ancylidae of South Africa. London and Dorking. Editado pelo autor. $82 \mathrm{p}$. 1925. Notes on South American Ancylidae I. Occ. Pap. Mus. Zool. Univ. Mich. 157: 1-7. 
Wautier, J. \& Odievre, M. 1961. Le genre Gundlachia Pfeiffer (Mollusque: Ancylidae) en France. Ses caractères. Verh. Internat. Verein Limnol. 14: 983-987.

Wrigth, C.A. 1963. The freshwater Gastropod Mollusca of Angola. Bull. Br. Mus. (Nat. Hist.) Zool. 10 (8): 447-528.

WuRTZ, C.B. 1951. Catalogue of Ancylidae of South and Central America and the West Indies, with description of new species. Nautilus 64 (4): 123-131.

ZiLCH, A. 1959/1960. Gastropoda. Euthyneura. In: O.H. SCHINDEWOLF (Ed.). Handbuch der Paläozoologie 6 (2). Berlin, Borntraeger, 834p.

Recebido em 30.X.1995; aceito em 02.VIII.1996. 